\title{
Intended Parents and the Problem of Perspective
}

\author{
Dara E. Purvis $\dagger$
}

ABSTRACT: When asked to identify the legal parents of a child, traditional family law principles look backwards in time, primarily to biology and to marriage. People using assisted reproductive technologies such as surrogacy, however, seek to manifest their intent to become parents with a forwardlooking temporal perspective, before a child is conceived and born. This mismatch leaves a parentage void for children of assisted reproductive technologies that should be filled through the use of prebirth parentage orders recognizing intended parents as legal parents-to-be. Intent will not only ameliorate specific problems for such children, but also deepen normative values of parenting such as planning for parenthood, and minimize irrelevant characteristics such as gender.

INTRODUCTION. 211

I. THE IMPORTANCE AND GOALS OF LEGAL PARENTAGE.............................213

A. Benefits of Legal Parentage by Statutory Definition .....................213

B. Goals of Defining Parentage ...................................................217

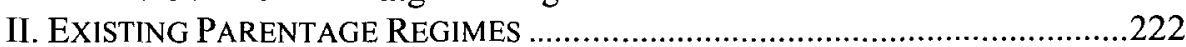

A. Marital Presumption..........................................................223

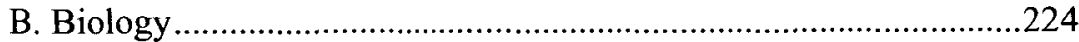

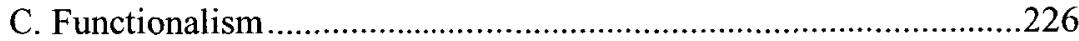

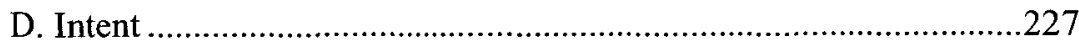

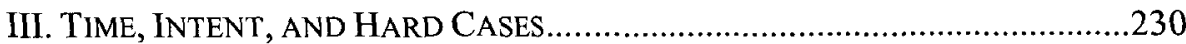

A. Pregnancy ...................................................................231

1. Dividing Pregnancy and Parentage: Assisted Reproductive Technologies ...................................................................231

2. Pregnancy, Parentage, and Time .......................................234

\begin{abstract}
$\dagger$ Visiting Assistant Professor, University of Illinois College of Law. Yale Law School, J.D. 2008; University of Cambridge, M.Phil. 2005; University of Southern California, B.A. 2003. I am grateful for the comments from and discussions with: Dennis E. Curtis, Daniel W. Hamilton, Dawn Johnsen, Dan Markel, Jerry L. Mashaw, Claire Priest, Arden Rowell, Jed Rubenfeld, Jane Rutherford, Naomi Schoenbaum, Ryan W. Scott, Nicola Sharpe, Deborah Widiss, and Susan Williams. Thanks also to participants in the Big Ten Untenured conference, Emerging Family Law Scholars conference, University of Illinois Faculty Roundtable, and Midwest Family Law Consortium for helpful comments and questions. An earlier version of this paper was presented at the Canadian Law and Economics Association 2012 annual conference. Finally, thanks to M. Laura Torre and Marbre Stahly-Butts for incisive and dedicated editing.
\end{abstract}




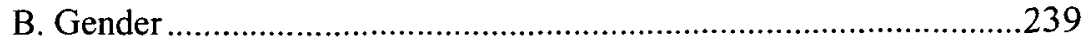

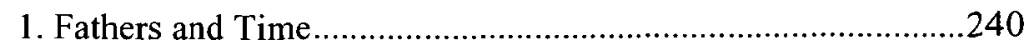

2. Constitutional Dimensions..............................................241

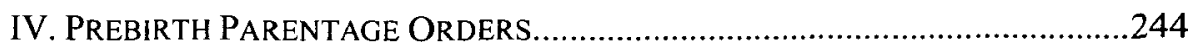

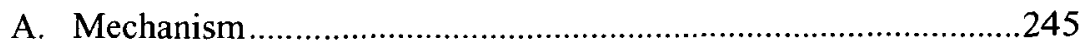

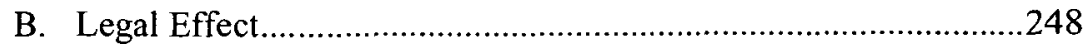

C. Benefits and Objections .........................................................249

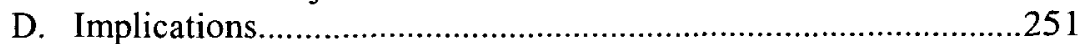

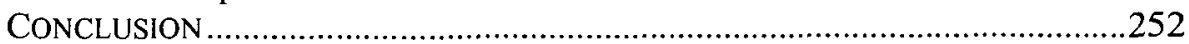

\section{INTRODUCTION}

In the context of nontraditional reproduction, the typically invisible rules of legal parentage often fail to provide children with support and other legal protections. Despite strong public policy concerns for the welfare of childrenin particular, the strength of child support obligations that at least in theory provide for a child's material needs-children conceived through the use of assisted reproductive technologies (ART) are excluded from legal protections. If an intended parent who plans to be the legal parent of a child conceived using ART dies before the child's birth, the child is deprived of tangible financial protections such as Social Security survivor benefits. To the extent there is a delay between birth and establishing the parentage of the intended parents, health insurance coverage for the child that is derivative of one of the intended parents will not be available to the child during that time. If married intended parents divorce before the child's birth, in many jurisdictions the intended parent without biological relationship to the child would lack any custody or visitation claim against a biological intended parent. The death of intended parents could also leave a surrogate mother as the only legally cognizable parent, with all the attendant responsibilities, of a child she never intended would be her own.

One reason for this is that existing rules of parentage formalize existing assumptions about parents, invisibly reinforcing uncontroversial patterns. Traditional rules of identifying parents codify intuitive presumptions about parental status: the father of a child born to a married woman is the woman's husband, questions of parentage can be easily answered with a blood test, or that the woman giving birth is the child's mother. With the advent of medical technologies such as sperm and egg donation, in vitro fertilization (IVF), and surrogacy, such suppositions are increasingly inaccurate. Moreover, recent cases such as Astrue v. Capato, in which the Supreme Court held that children conceived through IVF after the death of their biological father do not qualify 
for Social Security survivor benefits, demonstrate that current laws simply do not contemplate modern dilemmas arising from ART.'

Faced with examples of children being disadvantaged by legal determination of rules of parentage, judges and legislatures have begun to add intent to the methods of identifying legal parents. Two issues related to intent, however, remain problematic. First, because intent has been used thus far as a stopgap, it is not always clear in what circumstances intent to be a parent should have legal force, or how consistently intent is employed. Second, the normative power of intent has not been fully explored. It seems straightforward enough to use intent where a judge is faced with an egg donor, sperm donor, and gestational mother who all say, "I do not want to be the legal parent of this child," with two intended parents demonstrating their desire to parent the child. This is an efficient solution, and instinctively seems to be a good result for the child, but efficiency and instinct are not by themselves sufficient to justify a legal-parentage standard.

Intent has a powerful normative benefit, however, as the only parentage rule that recognizes adults who actively plan to become parents. Not all parents plan for their role, nor can intent become the single answer to identify parents in all circumstances. Intent should, however, be employed as a first and best rule for assigning legal parentage where it can be assessed with certainty. Using intent as a parentage standard where it can be most easily identified begins to integrate intent, which solves problems of too many parents, alongside other parentage rules such as biological connection, which solves problems of too few parents. Furthermore, intent solves many of the tangible problems that currently arise with nontraditionally conceived children.

One of the limitations of intent, obviously, is that it can be hard to assess. The context of ART, however, provides a clear opportunity for unambiguous prebirth expressions of intent that can and should be recognized by family courts. It is the contention of this article that in the context of ART, intended parents should be able to secure prebirth parentage orders that identify them as legal parents-to-be. This is a preliminary step incorporating intent into other parentage regimes such as genetic connection, using intent in a context in which it is already being inconsistently employed, and using unambiguous expressions of intent to identify parents for children in nontraditional circumstances who are currently underserved by the law. As a first step, prebirth parentage orders begin to take advantage of the normatively desirable and gender-neutral aspects of intent.

Section I explains the importance of determining legal parentage and assesses what the goals of a legal parentage regime are, concluding that facilitating advance planning for parenthood should be one goal of a parentage regime. Section II outlines existing theories of how to determine legal parents,

1. 132 S. Ct. 2021 (2012). 
and identifies the points in time at which each theory provides an answer of parentage. Section III explores two contexts in which allowing prebirth intent to determine legal parentage would address problems in identifying legal parents: pregnancy in the contexts of surrogacy and unwed fathers. Section IV proposes the use of prebirth parentage orders to settle the parentage of children conceived through surrogacy before their birth, not by eliminating existing laws, but providing intent as a "first best" option that can provide an answer to legal parentage.

\section{The IMPORTANCE AND GoALS OF LEgal PARENTAGE}

Parentage rules may at first glance seem unnecessary: adults care for children who are their extended family or foster children for long periods of time, and adults who wish to gain legal protection and recognition of that work may seek to adopt children. What, then, is the significance of legal parenthood? Section A explains the formal consequences of being recognized as a parent through statute, rather than seeking to adopt a child. Section B turns to the expressive function of law, assessing how parental statutes create and preserve specific normative views of what parenting is.

\section{A.Benefits of Legal Parentage by Statutory Definition}

As a threshold question, it is important to understand the significance of an individual being identified as the legal parent of a child through statutory definition rather than other means. "Statutory definition" means that one or two adults meet the definition of "legal parent" as outlined in state law, and no other adults do. It is the legal parenthood recognized by writing a parent's name on a child's birth certificate. This is the most common mechanism by which legal parenthood is created: uncontested, uncomplicated, and without formal hearing or intervention by the state.

The status of legal parentage is extremely important. Although an adult can be the caretaker of a child without legal-parent status (such as a foster parent), legal parentage has attendant benefits, such as long-term stability and clear lines of responsibility and obligation, that benefit the child in the long term. ${ }^{2}$ Furthermore, studies indicate that the emotional relationships between legal parent and child are stronger even than the relationship between a permanent caregiver and child. ${ }^{3}$ Having a legal parent as caregiver is thus beneficial for children both financially and emotionally.

2. See David D. Meyer, Family Ties: Solving the Constitutional Dilemma of the Faultess Father, 41 ARIz. L. REV. 753, 792-812(1999).

3. See David D. Meyer, A Privacy Right to Public Recognition of Family Relationships? The Cases of Marriage and Adoption, 51 VILL. L. REV. 891, 911 (2006); see also Margaret F. Brinig \& Steven L. 
Parental status is also immensely significant as a constitutional matter. Parental status grants constitutionally protected rights to determine the care, custody, and control of a child. The rights of a legal parent outweigh that of any non-parent, even if the non-parent has been the primary caretaker of a child. ${ }^{4}$ Parental autonomy in choosing whom a child may see, who may receive custody or visitation rights, and who may make decisions concerning care and control of the child is granted constitutional protection, which prevails over the interests of non-parent adults who may have significant relationships with the child. ${ }^{5}$

While the state may place some obligations on parents, such as education of the child, ${ }^{6}$ parents still have considerable flexibility in fulfilling even those baseline requirements. Although the state intervenes where it believes the level of parents' care has fallen below what the state deems minimal fitness, such interventions often take place where the state is already involved in the family's life, such as when the family is receiving welfare benefits. ${ }^{7}$ Termination proceedings have both substantive and procedural requirements aimed at rigorous protection of the legal parent's interests. ${ }^{8}$ The status of legal parent thus has tremendous legal significance, as it comes with near complete independence in decision-making and significant constitutional protection.

Despite its legal significance the status of legal parent is viewed in many ways as a natural right. But in order to assess parentage regimes from a blank slate, one must separate traditional markers of parenthood such as pregnancy from legal parentage. Particularly in the context of ART, there is an intuitive

Nock, How Much Does Legal Status Matter? Adoptions by Kin Caregivers, 36 FAM. L. Q. 449 (20022003).

4. In some circumstances, as discussed infra, the caretaker of a child might be identified as a de facto or psychological parent, and thus be granted some rights vis-à-vis the child. In such a case, however, the de facto parent either would actually become a legal parent by virtue of his or her relationship with the child or would be deemed to be something more than a complete legal stranger, but with lesser rights than a legal parent.

5. Susan Frelich. Appleton, Parents by the Numbers, 37 HOFSTRA L. REV. 11, 20 (2008); see also, e.g., Troxel v. Granville, 530 U.S. 57, 66, 69-70 (2000); Parham v. J.R., 442 U.S. 584, 602 (1979); Wisconsin v. Yoder, 406 U.S. 205, 232 (1972).

6. See, e.g., Yoder, 406 U.S. at 205.

7. See Elizabeth Bartholet, Guiding Principles for Picking Parents, 27 HARV. WOMEN's L.J. 323, 341 (2004).

8. Termination proceedings have two high substantive bars that must be met: first, the state must prove that termination of parental rights is justified by a specific statutory reason; and second, that termination of parental rights is in the child's best interest. Furthermore, termination of parental rights is subject to procedural requirements: the state must prove allegations made in a termination hearing by clear and convincing evidence, parents must be allowed to appeal even if they cannot afford ensuing costs such as paying for a copy of the trial transcript, and although the Supreme Court held that parents need not be provided counsel in all termination proceedings, it explained that appointed counsel could be required according to each case's facts, and pointedly remarked that "wise public policy" and "informed opinion" had "clearly come to hold that an indigent parent is entitled to the assistance of appointed counsel not only in parental termination proceedings, but also in dependency and neglect proceedings as well." Lassiter v. Dep't of Soc. Servs., 452 U.S. 18, 33-34 (1981); see also Catherine J. Ross, The Tyranny of Time: Vulnerable Children, "Bad" Mothers, and Statutory Deadlines in Parental Termination Proceedings, 11 VA. J. SOC. POL'Y \& L. 176, 186 (2004). 
sense that the adults who would traditionally be viewed as parents already have parental rights that must be either recognized by the law or at least weighed against the interests of the child and the state. For example, one commentator, in arguing against specific enforcement of surrogacy agreements, states that a regime that allows parties to make private surrogacy agreements but does not use the power of the state to enforce the agreements-which in practice would allow a surrogate who changed her mind to keep the child-_would retain ... the assumption (or ideology) of current law-that, ordinarily, parents will not give up their children. It would affirm that wanting to keep one's children, even where one has previously agreed otherwise, is not pathological or wrong, but rather understandable and defensible." This begs the question. "[B]efore a person can exercise the fundamental right to raise one's child, the State must deem that person to be a legal parent." ${ }^{10}$ Recognition of an adult as a legal parent is necessary before any legal rights accrue. Most of the time, there is no formal procedure by which legal-parentage status is recognized, because most of the time parental status seems self-evident through biological connectionand it is not the contention of this Article to start from a vacuum and eliminate parentage based on regimes such as biology. But in the abstract, if parentage is a blank slate-if there is no assumption that a pregnant woman is necessarily the legal mother of the child to whom she gives birth-we cannot speak of "her" child.

Parentage through statutory operation is not the only way that an adult can become the legal parent of a child: an adult can also adopt a child. Adoption, however, is a burdensome process with hurdles that are not present for parents identified through statute. Adoptions can be accomplished through different paths-both private and public agencies facilitate adoptions, " and stepparents may in some circumstances secure a second-parent adoption-but all share one crucial step: the finding by a judge that adoption is in the best interest of the child. By contrast, there is no judicially recognized burden of proof that must be met for so-called "natural" parenthood to be created. ${ }^{12}$

9. Katharine T. Bartlett, Re-Expressing Parenthood, 98 YALE L.J. 293, 335 (1988) (emphasis added); see also Marla J. Hollandsworth, Gay Men Creating Families Through Surro-Gay Arrangements: A Paradigm for Reproductive Freedom, 3 AM. U. J. GENDER \& L. 183, 186 (1994-1995) ("Our culture finds it morally repugnant and unacceptable for a woman to reproduce and then not raise the child.").

10. Mary Patricia Byrn \& Jenni Vainik Ives, Which Came First, the Parent or the Child?, 62 RUTGERS L. REV. 305, 313 (2010).

11. Private and public adoption agencies, it is worth noting, in practice operate quite differently. Private adoption is expensive, and almost exclusively places healthy, white newborns. Public adoptions are less expensive, often take more time, and are more likely to involve older children or children of minority races. See Jana B. Singer, The Privatization of Family Law, 1992 WIS. L. REV. 1443, 1479-86.

12. Indeed, Melanie Jacobs has characterized much of the debate regarding surrogacy as a fight to determine whether ART should be treated as an extension of procreative privacy or more like adoption. See Melanie B. Jacobs, Procreation Through ART, 35 CAP. U. L. REV. 399, 399 (2006). One developing area of overlap between the two is "embryo adoption," when embryos that would otherwise be discarded as the byproduct of ART are used by another couple. See Susan Frelich Appleton \& Robert A. Pollak, 
Furthermore, the best interest standard can be a rigorous hurdle. Adoption requires the state to make a host of judgments about the potential parents that the law does not permit to be made about so-called "natural" parents. As Susan Frelich Appleton described,

When a woman and a man engage in sexual relations and produce a child, the law ordinarily makes such activities the exclusive business of the couple. The couple need not receive state certification for recognition as suitable parents, and the resulting child instantly "belongs" to them, with all attendant parental prerogatives and responsibilities.

At the other end of the continuum lies adoption, a highly regulated activity, with the state deeply involved not just in terminating biological parents' rights but also in the screening and approval of adoptive parents, who must endure home visits, waiting periods and the risk of adoption nullification based on defects in the consent procured from the biological parents ... Adoption always entails judicial proceedings and requires a court's decree. ${ }^{13}$

The best interest test can also introduce factors that are particularly fraught for intended parents: for example, opening the door to arguments about whether same-sex couples are the appropriate or ideal parents for children. ${ }^{14}$ The best interest test is a broad inquiry that provides room for conflicting arguments regarding whether same-sex parents are the ideal parents for a child. ${ }^{15}$ Based on their marital status, unmarried cohabiting couples are viewed as less desirable parents, and in some cases face outright elimination as potential parents. ${ }^{16}$ Should the intended parents be a same-sex couple, the best

Response, Exploring the Connections Between Adoption and IVF: Twibling Analyses, 95 MINN. L. REV. HEADNOTES 60, 66 (2011), http://www.minnesotalawreview.org/wp-content/uploads/2011/05/AppletonPollak_PDF.pdf.

13. Susan Frelich Appleton, Adoption in the Age of Reproductive Technology, 2004 U. CHI. LEGAL F. 393, 410-11 (2004) (internal citations omitted).

14. Katharine M. Swift, Parenting Agreements, the Potential Power of Contract, and the Limits of Family Law, 34 FLA. ST. U. L. REV. 913, 943-47 (2007). Although the last formal prohibition on adoption by same-sex couples was struck down in 2010 , some practical statutory hurdles exist for samesex couples. For example, Utah, a state that does not allow same-sex marriage, prohibits a person cohabiting with a nonmarital partner from adopting, effectively blocking adoption by people in cohabiting same-sex relationships. See UTAH CODE ANN. 78B-6-117(3)(b) (West 2008); In re Matter of Adoption of X.X.G. and N.R.G., 45 So. 3d 79 (Fla. Dist. Ct. App. 2010).

15. See, e.g., Lynne Marie Kohm, Moral Realism and the Adoption of Children by Homosexuals, 38 NEW ENG. L. REV. 643 (2004).

16. See Richard F. Storrow, Rescuing Children from the Marriage Movement: The Case Against Marital Status Discrimination in Adoption and Assisted Reproduction, 39 U.C. DAVIS L. REV. 305 (2006); see also Jennifer L. Rosato, Children of Same-Sex Parents Deserve the Security Blanket of the Parentage Presumption, 44 FAM. CT. REV. 74, 74 (2006). 
interest test opens the door to arguments about the fitness of homosexuals to be parents.

By contrast, when legal parentage is determined by statute, no qualitative evaluation of the prospective parents is prospectively performed. Although the state may terminate parental rights if the standard of fitness is not met, such terminations are based upon conduct that has already taken place. ${ }^{17}$ Some commentators, such as Richard Storrow, have proposed that fertility clinics perform an assessment of prospective parents before assisting them in reproduction, ${ }^{18}$ but no jurisdiction currently requires any such evaluation. Legal parentage through statutory definition thus avoids the best interest inquiry and hurdle entirely.

Identification as legal parent through the application of statute, therefore, is a better method of securing parental rights, at least from the point of view of the potential parent. A legal parent identified through statute is recognized as having all the rights of a legal parent from the moment of the child's birth and is not subjected to the state intrusion characteristic of gaining legal parentage through operation of law such as adoption. Because the definition of legal parentage brings with it so many practical consequences for the identified parents, the law's selection of parents has normative connotations as to who the best parents are. The next section turns to tracing the connotations and goals of a legal-parentage regime.

\section{B. Goals of Defining Parentage}

Providing a child with legal parents has been described as "the first and most profound act a state takes under parens patriae," 19 the state's duty to protect citizens who cannot act for themselves. ${ }^{20}$ In one sense, a state's parentage laws simply have the practical effect of protecting some of its most vulnerable members. Laws also, however, have an expressive effect: the law identifies characteristics of parenting that are normatively desirable. Those principles will in turn channel adult conduct, by making ways of becoming

17. See Carter Dillard, Child Welfare and Future Persons, 43 GA. L. REV. 367, 445 (2009). It is worth acknowledging, however, that such termination proceedings are more likely to be brought where the state is already involved in some way in the parents' lives-if, for example, a parent is arrested or ACS is involved with the family. Furthermore, once the state has intervened in family life, particularly if one child has been removed from the home, the state may intervene as early as the birth of a subsequent child. Even in such cases, however, the intervention is framed as a termination of parental rights, not denial of parental status altogether.

18. See Richard F. Storrow, The Bioethics of Prospective Parenthood, 28 CARDOZO L. REV. 2283 (2007) (proposing that fertility clinics assess a minimum fitness level of prospective parents).

19. Byrn \& lves, supra note 10 , at 323.

20. BLACK'S LAW DICTIONARY 1221 (9th ed. 2009) (outlining the State's duty to protect "those unable to care for themselves"). 
parents "reasonable and even natural." 21 The laws that identify legal parents, therefore, embody what parenting should be. Analysis of existing laws, however, illustrates considerable confusion in the law. Many of the rules defining parentage further policy goals that are no longer paramount or even relevant today. Instead, a careful reading indicates that a beneficial characteristic-responsibility in parenting-is currently underserved by existing laws.

The broadest statement of purpose as to a parentage regime is to benefit children. This is different from the legal test, employed in adoption and custody determinations, of assessing a child's best interest. Best interest is evaluated by comparing more than one known potential outcome, such as two parents who are each asking for custody. Identifying rules of parentage, by contrast, is the abstract question of what kinds of parents the law should protect.

This question has not always been asked with an eye to what kinds of parents will benefit children. David D. Meyer, for example, explained that traditional parentage law was "driven significantly by the needs and interests of adults-a sense of the natural entitlement of genetic parents, for instance, or society's desire to protect marriage or enable the orderly transfer of wealth between generations." ${ }^{, 22}$ As the law has begun to incorporate greater concern for children, "the law often seems to be lurching unwittingly in opposite directions."23

A few threads of what functions parentage rules serve can be identified. First, parentage rules provide stability, meaning that one or two adults are identified permanently as the parents of the child. Although parentage can change in certain circumstances - the parents failing to meet minimum standards of fitness or choosing to give the child up for adoption - the presumption is that legal parentage is a status of indefinite duration. Second, responsibility for the child is placed upon the parents, rather than upon the state. Third, whatever the substance of the parentage rules, regimes have historically been reasonably clear so that parentage determinations are not made on a case-by-case basis. ${ }^{24}$ For obvious reasons, a parentage regime stating that children would be raised by the adult(s) who will most benefit the child would be unworkable in practice. ${ }^{25}$ Thus, defining characteristics to

21. Carl E. Schneider, The Channeling Function in Family Law, 20 HoFSTRA L. REV. 495, 498 (1992).

22. David D. Meyer, The Constitutionality of "Best Interests" Parentage, 14 WM. \& MARY BILL RTS. J. 857, 857 (2006).

23. David D. Meyer, Parenthood in a Time of Transition: Tensions Between Legal, Biological, and Social Conceptions of Parenthood, 54 AM. J. CoMP. L. 125, 136 (2006)

24. See Meyer, supra note 23, at 131.

25. Cf. Julia Halloran McLaughlin, The Fundamental Truth About Best Interests, 54 ST. LouIS U. L.J. 113-114 (2009) (arguing that children have a constitutionally protected fundamental right "to enjoy loving and nurturing parent-like relationships," although proposing that the right comes into play in custody, rather than parentage, determinations). 
benefit children must come "in the design of the regime rather than in its implementation in specific cases." 26

How, then, to define "benefit children" in principles that can be identified across individuals? One possible answer is biological relationship. A biological relationship between adult and child provides both a clear identification and possible qualitative reasons for better parenting, as some proponents of evolutionary biology argue. ${ }^{27}$

There are a few reasons, however, that biology alone cannot explain parentage laws as proxies for interests of the child. As an initial matter, there is considerable disagreement over the studies purporting to show better care by biological parents. ${ }^{28}$ In a detailed discussion of existing literature, June Carbone and Naomi Cahn conclude that the most complete assessment of the evolutionary theories paints a "complex picture in which paternal tendencies to father as many children as possible and to invest more in biological than nonbiological children are offset by maternal preferences and the role of intimate relationships in mediating paternal involvement." 29 There is thus considerable doubt over whether biological connection yields better parenting.

Setting aside the scientific debate as to whether genetic parents benefit children, it is clear that as a descriptive matter, family law has moved away from biology. There are multiple examples of reforms to parenting law that explicitly reject biological connection as a basis for parenthood, such as adoption, foster care, and second-parent adoptions by stepparents. Moreover, the Supreme Court has repeatedly rejected biological relationship as a trump card in disputes over parental rights. In the famous case Michael H. v. Gerald $D$. the Supreme Court rejected outright the claims of a man who was indisputably the biological father of a child because conception took place in an adulterous liaison. ${ }^{30}$ Another manifestation of this trend, discussed further in section III.B, is the Court's rejection of claims by biological fathers who are not married to the mothers of their children. ${ }^{31}$ Given that existing laws allow

26. June Carbone \& Naomi Cahn, Which Ties Bind? Redefining the Parent-Child Relationship in an Age of Genetic Certainty, 11 WM. \& MARY BILL RTS. J. 1011, 1016 (2003).

27. "Perhaps the most obvious prediction from a Darwinian view of parental motives is this: Substitute parents will generally tend to care less profoundly for children than natural parents, with the result that children reared by people other than their natural parents will be more often exploited and otherwise at risk." MARTIN DALY \& MARGO WILSON, HOMICIDE 83 (1988).

28. See Carbone \& Cahn, supra note 26, at 1026-39.

29. Id.at 1037. See also June Carbone \& Naomi Cahn, The Biological Basis of Commitment: Does One Size Fit All?, 25 WOMEN's RTS. L. REP. 223, 225 (2003-2004) (arguing that while pair-bonding into coupled relationships may be instinctual, long-term fidelity to those couplings is not).

30. 491 U.S. 645 (1972); see also Bartholet, supra note 7, at 326.

31. Linda S. Anderson, Just Because You Don't Want Kids Doesn't Mean I Can't Have Them: How Clarifying Definitions of "Parent" and "Procreate" Can Prevent the Indefinite Storage of Cryopreserved Embryos, 49 U. LoulSVILLE L. REV. 231, 238-40 (2010) (summarizing five Supreme Court cases rejecting biology alone as trigger for status as legal father). 
and even encourage parenting of nonbiological children, biology alone cannot be read to be a proxy for best parenting. ${ }^{32}$

Indeed, the law has increasingly focused on relationships created between a child and an adult that are meaningful to the child, and has found those relationships to be worthy of legal protection. ${ }^{33}$ There is something traditional in this focus on relationship over biology, as the marital presumption undoubtedly declared husbands to be the legal fathers of children who were not their biological offspring. Ira Mark Ellman aptly pointed out that although "the law's historic emphasis on social paternity owed much to scientific ignorance, it often produced sensible results.",34

A functional relationship, however, is created after the child's birth, and a parentage regime must be able to identify what characteristics are important at birth, before any relationship develops. Historically, one important aspect of social paternity was providing financial support for children when a single mother would have been unable to do so. Such financial care has two benefits. First, by establishing clear lines of responsibility from wealth-generating adult to child, the child's needs are less likely to be provided by the state. ${ }^{35}$ Second, and more charitably toward the lawmaker, a child whose needs are met by his or her caretakers rather than public benefits will likely receive more and better financial support. ${ }^{36}$ Financial support alone, however, cannot be a proxy for best interests. Indeed, there is no formal financial test for "natural"

32. The growing numbers of paternity disestablishment cases, in which a married man discovers the marital children he believed to be his biological children are in fact the product of adultery, also indicate that courts and legislatures across the nation are uncomfortable with the idea of biology alone determining parentage. See Melanie B. Jacobs, My Two Dads: Disaggregating Biological and Social Paternity, 38 ARIZ. ST. L.J. 809, 838-40 (2006) [hereinafter Jacobs, My Two Dads]; Melanie B. Jacobs, When Daddy Doesn't Want to be Daddy Anymore: An Argument Against Paternity Fraud Claims, 16 YALE J.L. \& FEMINISM 193 (2004).

33. Bartholet, supra note 7 , at 327.

34. Ira Mark Ellman, Thinking About Custody and Support in Ambiguous-Father Families, 36 FAM. L. Q. 49, 77 (2002).

35. Katharine K. Baker, Bionormativity and the Construction of Parenthood, 42 GA. L. REV. 649, 692 (2008) ("The private construction of parenthood allows the state to absolve itself of economic responsibility for children.") See also Bartholet, supra note 7, at 339 ("At present, parentage policy is unduly driven by the felt need to find a bill payer.").

36. But see Bartholet, supra note 7, at 339 ("We should also be prepared to surrender the traditional idea that parents provide all the financial support that children need."). 
parenthood $^{37}$ and financial insolvency is not sufficient in itself to terminate parental rights. $^{38}$

When describing characteristics of parenting that the law should encourage, several commentators have articulated the value of considering the impact of actions on children and behaving accordingly. Elizabeth Bartholet argues that family law must be reformed "to place greater emphasis on parental responsibilities and children's rights to receive responsible parenting." 39 Barbara Bennett Woodhouse has proposed a philosophy of parenting as providing "concrete service to the needs of the next generation." Dowd's nurturing principle would define parentage through care. ${ }^{41}$

A common thread in these various descriptions of responsible, nurturing, child-focused parenting is advance planning. Responsible parents make decisions for the future based upon the impact that their choices will have on their children. This need not mean specifically planning for a pregnancy-it can be choosing one job over another based on greater potential for salary advancement, or because one position allows for a flexible work schedule enabling the parent to be a part-time caretaker. It could be choosing to begin taking prenatal vitamins once pregnancy is discovered, or it could even be choosing to marry after an unexpected pregnancy. It could be devoting considerable time, money, and planning for a child long before the child is even conceived, such as in the case of parents who seek to have a child through ART. $^{42}$

This is not to say that planned pregnancy, or any specific advance choice, should be a requirement for parental rights. This Article does not propose to strip parenthood from women who did not take prenatal vitamins. But to the extent that parentage laws serve expressive and channeling functions, by recognizing or protecting a certain type of behavior, it seems incongruous to value responsibility and the types of planning described above-which as a descriptive matter we already do-and yet not facilitate planning pre-

37. But see State v. Oakley, 629 N.W.2d 200 (Wis. 2001) (holding that a probation condition requiring a father who had intentionally refused to pay child support not to father any more children did not unconstitutionally burden his fundamental rights). Financial insolvency is not sufficient in itself to terminate parental rights, but the consequences of poverty-a lack of food security, for example may lead to termination proceedings. But cf. Katharine K. Baker, Bargaining or Biology? The History and Future of Paternity Law and Parental Status, 14 CORNELL J. L. \& PUB. POL'Y 1, 12 (2004) ("Vesting parental rights in those who spend money with the intent to support a child helps ensure that the child will be supported.").

38. But cf. Katharine K. Baker, Bargaining or Biology? The History and Future of Paternity Law and Parental Status, 14 CORNELL J. L. \& PUB. POL'Y 1, 12 (2004) ("Vesting parental rights in those who spend money with the intent to support a child helps ensure that the child will be supported.").

39. Bartholet, supra note 7 , at 337 (emphasis removed).

40. Barbara Bennett Woodhouse, Hatching the Egg: A Child-Centered Perspective on Parents' Rights, 14 CARDOZO L. REV. 1747, 1815 (1993).

41. See NANCY E. DOWD, REDEFINING FATHERHOOD 213 (2000).

42. Cf. Bartlett, supra note 9, at 295 (arguing that the law's view of parenthood should be "based on responsibility and connection," although also arguing against specific enforcement of surrogacy agreements). 
conception. Planning for parenthood should be neither necessary nor sufficient to generate parental status, but it should not be irrelevant to normative discussions of parentage regimes.

The next section thus turns to evaluating existing theories of parentage. Historical parentage rules serve purposes such as ensuring financial support for children that were important when the rules developed, and which may have lasting importance today. In addition to providing for the material support of children and creating a reasonably efficient method of identifying parents, however, the legal parentage regime should also assist adults who seek to prospectively establish legal responsibilities as parents. ${ }^{43}$ The next section assesses whether extant regimes do so.

\section{EXISTING PARENTAGE REGIMES}

There is growing variety in how states define parentage through statute. ${ }^{44}$ Whereas historically, the law assumed that parents became parent either through sexual reproduction or formal adoption, ${ }^{45}$ today parents may also be created by adopting stepchildren, creating a significant relationship with a child, being married to a child's mother, or intending to create a child through ART. Evaluating existing theories of parentage as to whether each facilitates a prospective view of planning for parenthood, it becomes apparent that only one theory-intent-allows a truly forward-looking perspective. The other alternatives, the marital presumption, biological connection, and functionalist theories, make a backward-looking assessment of parenthood in two ways: first, the assessment of parentage is made only after the child is born; ${ }^{46}$ second, the assessment looks backwards to a fact determined at birth or even after birth to determine who the child's legal parents are. This is not to conclude that intent should be the sole factor determining parentage. It emphasizes, however, both tangible and normative advantages to intent that existing rules do not provide.

43. Note that this discussion of the goals of parentage regimes does not address some of the specific questions of mechanics, such as the growing question of whether a child should have a maximum of two parents, or whether legal recognition of three or more legal parents would benefit children. See Laura Nicole Althouse, Three's Company? How American Law Can Recognize a Third Social Parent in SameSex Headed Families, 19 HASTINGS WOMEN'S L.J. 171, 209 (2008); Nancy E. Dowd, Multiple Parents/Multiple Fathers, 9 J.L. \& FAM. STUD. 231 (2007); Melanie B. Jacobs, Why Just Two? Disaggregating Traditional Parental Rights and Responsibilities to Recognize Multiple Parents, $9 \mathrm{~J} . \mathrm{L}$. \& FAM. STUD. 309 (2007); Laura T. Kessler, Community Parenting, 24 WASH. U. J. L. POL'Y 47 (2007).

44. See generally Courtney G. Joslin, Interstate Recognition of Parentage in a Time of Disharmony: Same-sex Parent Families and Beyond, 70 OHIO ST. L.J. 563 (2009) (arguing that parentage is an increasingly contested area of law, particularly in the context of same-sex families).

45. David D. Meyer, The Constitutionality of "Best Interests" Parentage, 14 WM. \& MARY BILL RTS. J. 857, 859 (2006).

46. See Byrn \& Ives, supra note 10, at 307 ("A closer look at state parentage statutes further demonstrates that legal parents do not exist until after a child is born."). 


\section{A. Marital Presumption}

The marital presumption specifies that if a man is married to a woman who gives birth to a child, he is presumed to be the father of the child, although that presumption can be rebutted or disavowed to some extent. The marital presumption is one of the oldest rules establishing parentage, and was historically "one of the strongest known to the law." currently apply some form of the marital presumption, although the majority allow rebuttal of the presumption if it is in the child's best interests. ${ }^{48}$ Some reforms even propose expanding the marital presumption as more appropriate for families increasingly unrelated by biology: as legal recognition of same-sex partnerships has expanded, some scholars have proposed that a marital presumption could serve policy goals even though its function as a legal fiction of biological parentage would be self-evidently false. ${ }^{49}$

The marital presumption served a number of important policy goals when it was first developed: it simplified family relationships before genetic relationships could be ascertained, ${ }^{50}$ avoided branding children as the illegitimate products of adulterous liaisons, ${ }^{51}$ and assigned support obligations for children who would otherwise be destitute. ${ }^{52}$

Given the vast changes in legal and societal views of marriage in the last century, however, including the advent of no-fault divorce, ${ }^{53}$ equalized treatment of nonmarital children, and growing acceptance of unmarried cohabiting and same-sex relationships, the functions originally performed by the marital presumption are obsolete. ${ }^{54}$

Although the marital presumption once furthered policies working to the benefit of children, it no longer does so in the modern context in which society and families are no longer organized strictly around marital relationships. Furthermore, the marital presumption does not support a forward-looking, planning perspective toward parenthood. There is a single point in time,

47. Susan Frelich Appleton, Presuming Women: Revisiting the Presumption of Legitimacy in the Same-Sex Couples Era, 86 B.U. L. REV. 227, 232-33 (2006).

48. Id. at 234-36.

49. Nancy D. Polikoff, A Mother Should Not Have to Adopt Her Own Child: Parentage Laws for Children of Lesbian Couples in the Twenty-First Century, 5 STAN. J. C. R. \& C.L. 201, 215 (2009); see also Appleton, supra note 47, at 271.

50. Janet L. Dolgin, Choice, Tradition, and the New Genetics: The Fragmentation of the Ideology of Family, 32 CONN. L. REV. 523, 527 (2000).

51. Particularly before Harry Krause's groundbreaking work in the 1960s, the stigma of illegitimacy had profound legal implications for the child. See, e.g., Harry D. Krause, Bringing the Bastard into the Great Society-A Proposed Uniform Act on Legitimacy, 44 TEX. L. REV. 829, 830 (1966).

52. Appleton, supra note 47 , at 247.

53. See Theresa Glennon, Somebody's Child: Evaluating the Erosion of the Marital Presumption of Paternity, 102 W. VA. L. REV. 547, 559-62 (2000).

54. See Linda C. McClain, Love, Marriage, and the Baby Carriage: Revisiting the Channeling Function of Family Law, 28 CARDOZO L. REV. 2133 (2007). 
generally at the time of birth, in which a marriage either exists or does not exist, and parentage is assigned accordingly. In theory, some couples planning ahead might be able to marry in advance of birth for the purpose of gaining legal benefits bestowed by a marital presumption, but for many couples, marrying to gain parental status would be impossible. ${ }^{55}$ For others, the legal consequences of marriage unrelated to children-termination of certain benefits, for example ${ }^{56}$-mean that gaining parental status might mean sacrificing other legal benefits that would advantage the future child. Marriage is not an accurate proxy for measuring planning behavior, and does not serve a forward-looking perspective.

\section{B. Biology}

A second parentage rule, largely arising from the historical dominance of the marital presumption, is biology: parentage as determined by identifying who has a biological ${ }^{57}$ relationship with the child. Although biological parentage is now regarded as natural and self-evident, it is a relatively recent development. Due to an inability to determine biological relationships with any certainty until the middle of the twentieth century, historically the law had "little interest" in who a child's biological parents-or at least biological father-were. ${ }^{58}$

Since reliable tests are now capable of identifying with certainty the biological relationship of an adult and child, legal parentage is seen to "follow[] easily from recognition of that natural fact." ${ }^{, 59}$ Such "natural" legal parentage is now seen as a universal rule, justifying the strong modern imposition of child support obligations where only a few decades ago children born to unmarried mothers were deemed not to have legal fathers. ${ }^{60}$

Biology has also been adopted as dispositive-outweighing other conceptions of parentage-by more than one court in disputes over parentage.

55. For example, same-sex couples or couples in which one person is not yet legally divorced from a previous spouse.

56. Such as alimony from a previous marriage. See Cynthia Lee Starnes, One More Time: Alimony, Intuition, and the Remarriage-Termination Rule, 81 IND. L.J. 971, 972-73 (2006).

57. I use "biological" as interchangeable with "genetic," although some commentators also use biological to indicate a bodily relationship with the fetus or child-for example, describing a gestational surrogate as biologically related to the child. For purposes of this paper, I use "biological relationship" to mean a person whose gamete, combined with another, created the fetus.

58. Polikoff, supra note 49, at 208; see also Janet L. Dolgin, Biological Evaluations: Blood, Genes, and Family, 41 AKRON L. REV. 347, 353 (2008); Susan E. Dalton, From Presumed Fathers to Lesbian Mothers: Sex Discrimination and the Legal Construction of Parenthood, 9 MICH. J. GENDER \& L. 261, 267-68 (2003).

59. Meyer, supra note 23 , at 125-26.

60. A particularly clear embodiment of the modern principle can be found in welfare reform's emphasis on identifying biological fathers of children whose mothers receive public benefits in order to impose child support obligations on them. See Jacobs, My Two Dads, supra note 32, at 822; Jane C. Murphy, Legal Images of Fatherhood: Welfare Reform, Child Support Enforcement, and Fatherless Children, 81 Notre DAME L. Rev. 325 (2005). 
In Alison D. v. Virginia M., two women in a same-sex relationship each had one child through artificial insemination. The two ended their relationship, but for several years allowed the other regular visits with the other child, approximating the custody arrangements of many divorced biological parents. Virginia eventually reduced and then terminated contact between her biological child and Alison. After Alison sued for visitation rights, the New York Court of Appeals ruled that because Alison was a "biological stranger" to the child, she had no parental status or rights. ${ }^{61}$ Biological relationship thus can have perverse effects as a parentage test, taking away a parental figure important to the child. This effect is magnified in the context of surrogacy: strict adherence to biology has occasionally resulted in a court determining that a genetic surrogate and an intended father (generally seeking to raise with his wife a child created through the surrogate's egg and his sperm) are the two legal parents of a child. $^{62}$

For obvious reasons, biological relationship is a determination made only after birth. ${ }^{63}$ Indeed, some of the current more controversial uses of biology are explicitly backward-looking, such as paternity disestablishment, in which a married man who has raised a child with his wife for some period of time discovers that the child he thought was the biological child of himself and his wife was in fact fathered by another man, and seeks to remove his parental status and parental obligations.

61. 572 N.E.2d 27, 28 (N.Y.1991); see also Paula L. Ettelbrick, Who Is a Parent?: The Need to Develop a Lesbian Conscious Family Law, 10 N.Y.L. SCH. J. HUM. RTS. 513, 522-32 (1993) (author represented Alison D).

62. Additionally, although the New York Court of Appeals found in this instance that biological relationship was the sole test for parenthood, there is an open market in gametes ensuring that biology cannot answer all parentage questions, as egg and sperm donation allows donors to terminate parental rights. Martha M. Ertman, What's Wrong with a Parenthood Market? A New and Improved Theory of Commodification, 82 N.C. L. REV. 1, 15-21 (2003). After the court's determination, in at least some cases the intended father has been granted custody and then used economic or other nonlegal pressure to cut off the surrogate's access to the child. The end result is thus the worst of both worlds: the child no longer has any legal relationship to the intended mother, so should the intended and legal father die or divorce the intended mother, the child has little legal protection for his or her relationship with the intended mother; and yet the legal relationship of the genetic surrogate with the child has led to no added relationship for the child. See In re Marriage of Moschetta, 30 Cal. Rptr. 2d 893 (Ct. App. 1994); In re Baby M, 537 A.2d 1227 (N.J. 1988); see also Deborah H. Wald, The Parentage Puzzle: The Interplay Between Genetics, Procreative Intent, and Parental Conduct in Determining Legal Parentage, 15 AM. U. J. GENDER SOC. POL'Y \& L. 379, 386-87 (2007). This is not to say, obviously, that legal parentage should acquiesce in the possibility of economic or other pressure by more affluent parents. It highlights, however, the unhelpful practical consequences of biology trumping factors evaluated from the child's perspective.

63. Technology is advancing such that prebirth genetic testing might one day be widely available, but at present such testing is relatively uncommon. See Andrew Pollack, Before Birth, Dad's ID, N.Y. TIMES, June 20, 2012, at B1. 


\section{Functionalism}

Third, a modern reform in definitions of parentage is to include a functional theory, sometimes called de facto or psychological parenthood. ${ }^{64}$ Functional theories are premised explicitly on protecting the child's emotional and psychological well-being. The theories are influenced by attachment theory from child psychology, which posits that people with important relationships to a very young child cannot be removed from the child's life without serious emotional and psychological trauma. ${ }^{65}$ The "emotional bonds that develop... as a result of shared daily life" are thus deemed important in the child's interest. ${ }^{66}$ Under a functional view of parentage, a functional parent may either be recognized outright as a legal parent or be deemed to have a secondary legal relationship to the child that, while not rising to the level of legal parent, is something more than standing as a legal stranger to the child. Functional parentage theories thus directly contradict biological-based theories.

Functional theories have gained significant legal traction, although not always to the same level of parentage outright. For example, in 2000, the Rhode Island Supreme Court confronted a question of functional parenthood in a same-sex relationship in Rubano v. DiCenzo. A long-term cohabiting lesbian couple decided to start a family: one partner became pregnant through artificial insemination, and the two raised the resulting child as co-parents for four years. After they ended their relationship, the biological mother of the child sought to terminate her ex-partner's relationship with the boy. The Rhode Island Supreme Court not only held that state statutes permitted recognition of a de facto parent-child relationship, but also specifically noted that a biological relationship was not a requirement to show such de facto parentage. ${ }^{67}$ Similarly, model rules such as the Uniform Parentage Act (UPA) and ALI endorse functional parenthood. The UPA, for example, presumes that a man is the father of a child if he lives with the child and holds the child out as his own for the first two years of the child's life, regardless of any biological relationship with the child or marital relationship with the child's mother. ${ }^{68}$

64. See Katharine T. Bartlett, Rethinking Parenthood as an Exclusive Status: The Need for Legal Alternatives when the Premise of the Nuclear Family Has Failed, 70 VA. L. REV. 879, 944, 946 (1984); see also J. Herbie DiFonzo \& Ruth C. Stern, The Winding Road from Form to Function: A Brief History of Contemporary Marriage, 21 J. AM. ACAD. MATRIMONIAL L. 1, 36-39 (2008).

65. See Barbara L. Shapiro, "Non-Traditional" Families in the Courts: The New Extended Family, 11 J. AM. ACAD. MATRIMONIAL L. 117, 131-32 (1993)..

66. V.C. v. M.J.B., 748 A.2d 539, 550 (N.J. 2000).

67. 759 A.2d 959, 967-68 (R.I. 2000); see also V.C. v. M.J.B., 748 A.2d 539 (N.J. 2000) (holding that a New Jersey woman had established psychological parenthood with respect to the biological child of her lesbian ex-partner); Richard F. Storrow, Parenthood by Pure Intention: Assisted Reproduction and the Functional Approach to Parentage, 53 HASTINGS L.J. 597, 672-73 (2002).

68. See Melanie B. Jacobs, Applying Intent-Based Parentage Principles to Nonlegal Lesbian Coparents, 25 N. ILL. U. L. REv. 433, 436-37 (2005); see also Melanie B. Jacobs, Micah Has One Mommy and One Legal Stranger: Adjudicating Maternity for Nonbiological Lesbian Coparents, 50 BUFF. L. REV. 341, 371-72 (2002). 
A functional understanding of parenthood, however, by definition does not foster advance planning: a functional relationship can be created only after birth, once the potential parent has had an opportunity to build a relationship with the child. ${ }^{69}$ Furthermore, functional parenthood is also a broader concept than legal parentage determinations, as a functional parent who may have a claim for visitation rights may still not be a legal parent, with all the attendant responsibilities and rights. ${ }^{70}$

\section{Intent}

Finally, intent theories of parenthood focus on the intent of parties involved in the creation or care of a child vis-à-vis the child's legal parents. The theory is straightforward: "[ $\mathrm{t}]$ he law grants parental rights and responsibilities to those who caused a child to come into being with the intent of parenting that child once it was born." 71 Intent is the only regime that facilitates advance planning for a child, as by definition it takes a forwardlooking perspective as to parenthood. In this sense intent-based regimes serve important policy goals, such as facilitating responsible parenting, without replicating the flaws of earlier regimes such as the marital presumption. ${ }^{72}$

Intent, however, is a radical change from past regimes. As Katharine Baker pointed out, "[t]he problem, of course, is that the system is wholly inconsistent with bionormativity and paternity doctrine, the purposes of which are and always have been to make men who did not intend to parent, parents."73 Furthermore, there are several different ways intent might be assessed. One relatively minimal incorporation of intent is to center it on partnered couples, almost as marital presumption "lite," stating that the consenting partner of a person undergoing ART is also a legal parent. Such intent-based measures have won approval in New Mexico and the District of Columbia. ${ }^{74}$ One step further than this is to recognize an implicit contract rather than explicit consent at the point of conception. For example, a New Jersey court found that a sperm donor's "active participation" in the process of medical insemination

69. At least one scholar has proposed a prebirth functional test of "nurturing" to identify a "birthfather," but the concept has not yet been adopted in practice. See Nancy E. Dowd, Parentage at Birth: Birthfathers and Social Fatherhood, 14 WM. \& MARY BILL RTS. J. 909, 913 (2006).

70. For this reason, functional parenthood highlights the growing discussion of whether a child may logically or even ideally have more than two "parents." See Baker, supra note 37, at 64-65.

71. Baker, supra note 35 , at 701 .

72. See Marjorie Maguire Shultz, Legislative Regulation of Surrogacy and Reproductive Technology, 28 U.S.F. L. REV. 613, 618 (1994) ("Intention and biology are often mutually reinforcing in family design. When they are not, I would have the law prioritize intention and deliberative commitment over genes and gendered reproductive function.").

73. Baker, supra note 35 , at 701 .

74. Polikoff, supra note 49 , at 233. 
demonstrated his intent to "assume the responsibilities of parenthood." Similarly, the Colorado Supreme Court held that the parental status of a sperm donor depends upon the intent of the donor and the mother at the time of conception. ${ }^{76}$ For this reason, many scholars have put considerable thought into the format and substance of how to make intent clear through contract so that intent to be a parent cannot be accidentally expressed. ${ }^{77}$

In order to fully map out intent as a parentage regime, two major ambiguities must be resolved. First, there is a question of whether intent is the sole parentage regime, and if not, where it falls in relation to other regimes. One way intent has been employed by courts is to provide legal parents where traditional regimes do not, as in In re Marriage of Buzzanca ${ }^{78}$ In that case, a married couple had planned to have a child through the use of donated egg, donated sperm, and a gestational surrogate. During the pregnancy, the Buzzancas divorced, and the husband claimed in his divorce petition that there were no children of the marriage. A California appellate court held that both the Buzzancas were the legal parents of the child. Significantly, however, the gestational surrogate "also appeared in the case to make it clear that she made no claim to the child." ${ }^{79}$ It is unclear what the impact would have been had the surrogate argued that she was the legal mother, as the court notes that under California statute legal motherhood could be established by giving birth. ${ }^{80}$

The same California appellate court found in Elisa B. v. Superior Court that a former lesbian partner was the legal parent of children conceived during their relationship and had to pay child support to her ex-partner. ${ }^{81}$ Again, however, no other potential parent existed to make a conflicting claim - and the plight of the single-parented children was highlighted by the fact that the custodial and biological mother was dependent on public assistance without her former partner's support. ${ }^{82}$ Similarly, a Florida court refused to enforce a contract establishing that a sperm donor would have no parental status or

75. C.M. v. C.C., 377 A.2d 821, 824-5 (N.J. Juv. \& Dom. Rel. Ct, Cumberland County 1977). The case, one of the early examples of a court grappling with sperm donation, had facts that complicated the court's analysis. The sperm donor was in a romantic relationship with the mother at the time of conception, although the conception itself was not accomplished through sexual intercourse, and the donor remained in a relationship with the mother (and to an extent to the child) for three months following the conception. Id. at 821-22.

76. In re R.C., 775 P.2d 27 (Colo. 1989); see also Baker, supra note 37, at 27-28 (discussing the case).

77. See Harvey L. Fiser \& Paula K Garrett, It Takes Three, Baby: The Lack of Standard, Legal Definitions of "Best Interest of the Child" and the Right to Contract for Lesbian Potential Parents, 15 CARDOZO J.L. \& GENDER 1 (2008).

78. 61 Cal. App. 4th 1410 (1998).

79. Id. at 1412 .

80. Id.

81. 117 P.3d. 660 (2005).

82. The biological mother asserted that the two had decided that she would be a stay-at-home mother. Id. at 663 . 
obligations toward his biological child because the donation took place through the "usual and customary manner" rather than "reproductive technology.,"83

Another view, influentially chronicled by Melanie Jacobs, is of intent as a tiebreaker when other regimes fail to provide an answer. ${ }^{84}$ For example, in Johnson v. Calvert, the California Supreme Court looked to the intent of parties involved in a surrogacy agreement. The court only looked to intent, however, after concluding that California statutes determining maternity failed to answer which woman-the biological mother who had donated an egg, or the gestational surrogate who had given birth-was the legal mother of the child. After determining that both women had an equal claim under state law, the court concluded that "she who intended to procreate the child-that is, she who intended to bring about the birth of a child that she intended to raise as her own-is the natural mother under California law." 85

Jacobs summarized two contexts in which intent has been used to resolve ambiguities or supplement existing regimes: first, intent as a rule that can be applied before any functional relationships could have been formed; second, intent as a tie-breaker between two individuals claiming the same parental status. $^{86}$

There is little consensus as to how intent interacts with other understandings of parentage. It seems obvious that absent a fundamental shift in the support of children, a pure intent regime, in which adults were not considered legal parents unless they consented to conception of the child, is unworkable. ${ }^{87}$ Yet if a hierarchy of regimes is created, in practice it seems that intent is used most often as a last resort, either when other rules do not distinguish between two potential parents, or the other rules are not applicable because no other potential parents exist.

Second, there is considerable variation as to the point at which intent is operative. Most scholars discussing intent as a parentage regime have focused on the moment of conception as the determinative point. ${ }^{88}$ Statutes establishing that the husband of a married woman who undergoes artificial insemination is

83. Budnick v. Silverman, 805 So.2d 1112, 1114 (Fla. Dist. Ct. App. 2002). Cf. Jhordan C. v. Mary K., 179 Cal. App. 3d 386, 393 (Cal. Ct. App. 1986) (holding that one of the justifications for requiring physician involvement in $\mathrm{Al}$ "is that the presence of a professional third party such as a physician can serve to create a formal, documented structure for the donor-recipient relationship, without which... misunderstandings between the parties regarding the nature of their relationship and the donor's relationship to the child would be more likely to occur").

84. See Jacobs, My Two Dads, supra note 32, at 818-20.

85. 851 P.2d 776, 782 (Cal. 1993).

86. Jacobs, supra note 68 , at $440-41$.

87. I will explore the tension between child support and intent further in future work.

88. See, e.g., John Lawrence Hill, What Does It Mean to be a "Parent"? The Claims of Biology as the Basis for Parental Rights, 66 N.Y.U. L. REV. 353, 358 (1991) ("[T]he intended parents should be legally recognized from the time of conception."). 
the legal father of any resulting child so long as he consented to the AI procedure also take this conception-centered view. ${ }^{89}$

In practice, however, intent has been assessed at different points. As discussed above, in Johnson $v$. Calvert the court looked to intent at the time of conception. In the later case $K M v$ v. $E G$, however, the California Supreme Court assessed the intent of a lesbian couple in which one partner donated her egg to be implanted in the other. ${ }^{90}$ Interestingly, the court did not assess the intent at the time of conception, which was arguably that the egg donor partner did not intend to be a mother to the resulting twin children, as she signed a standard egg donor consent form explicitly disavowing any parentage claim. Rather, the court assessed intent as to what the practical responsibilities of each partner would be at the point that they came home from the hospital with the children, and determined that whatever the significance of the consent form-setting aside the donor partner's argument that she had not understood the form, and thought she and her partner were in agreement that they would be co-parentsthe intent when the twins came home was that the two women would live together and parent the children together. ${ }^{91}$ The intent assessed, therefore, was post-birth intent, which trumped even the pre-conception intent expressed in writing by the parties. Post-birth intent, moreover, may implicitly lie behind definitions of social paternity that require the father to "hold out" the child as his own, taking public affirmation of fatherhood as proof of intent or consent to be a father.

Of existing parentage theories, therefore, intent is the only option that facilitates advance planning for parenting. As intent has been used by the courts, however, its benefits as a theory are not fully realized, as intent is taken into account inconsistently and only in limited circumstances. The next section explores two circumstances in which intent has not yet been utilized by the courts: the intent of pregnant surrogates not to be parents, and the intent of unwed fathers to be parents. These contexts further demonstrate the benefits of intent as one tool to determine parentage.

\section{TIME, INTENT, AND HARD CASES}

As discussed above, courts have looked to the intent of potential parents in limited circumstances: when other parentage regimes fail to identify a legal parent, or as a tiebreaker, when state law does not prioritize between two regimes that provide simultaneous and conflicting answers. Examining two

89. See, e.g., CAL. FAM. CODE $§ 7613$ (a) (West 2011).

90. 117 P.3d 673 (Cal. 2005). This case stood in stark contrast to the earlier Nancy S. v. Michele G., 279 Cal. Rptr. 212 (Cal. Ct. App. 1991), in which a California court rejected the use of intent to determine legal parentage in the context of lesbian co-parents because assessing intent would require "elusive factual determinations." $I d$. at 219.

91. KM v. EG, 117 P.3d at 679. 
types of hard cases in determining parentage - the desire of a surrogate to give birth to a child to whom they are not the legal mother, and the desire of unwed fathers to secure parental rights and status - demonstrates the potential value of prebirth intent to be a parent. Section A discusses the exceptionalism of pregnancy, which counsels that the expressed intent of pregnant women is not to be trusted, at least if that intent is not to see themselves as a mother. By contrast, Section B shows the reverse of this assumption, treating unmarried men as unwilling fathers. Legal recognition of intent therefore has the potential not only to serve some of the tangible ambiguities of surrogacy, but to begin to counter harmful gender stereotypes.

\section{A. Pregnancy}

Until recently, it was hard to imagine a pregnant woman giving birth to a child and not being named the mother. The development of surrogacy, however, divides pregnancy from typical understandings of parentage. Moreover, by splitting pregnancy away from other parentage regimes such as biology, surrogacy highlights how parentage laws do not credit the intent of a pregnant woman.

\section{Dividing Pregnancy and Parentage: Assisted Reproductive Technologies}

Today, the use of ART has become relatively routine practice. Approximately 250,000 babies each year-approximately four percent of live births-were conceived through some form of ART. ${ }^{92}$ New technologies of ART have also widened the spectrum of available options. Artificial insemination was the first technology to gain widespread acceptance, then in vitro fertilization-sometimes referred to as "test tube babies"-moved conception to outside of the body.

The use of surrogacy was developed more recently. ${ }^{93}$ There are two types of surrogacy: first, genetic surrogacy occurs when a woman becomes pregnant using sperm donated by the intended father (who may be married to the intended mother), and thus carries to term a fetus that is her own biological child. Advances in medical technology have made the second type, gestational surrogacy, more common: both egg and sperm are donated and then implanted in the uterus of the gestational surrogate, who carries to term a fetus to which

92. J. Herbie DiFonzo \& Ruth C. Stern, The Children of Baby M., 39 CAP. U. L. REv. 345, 353 (2011).

93. In the Old Testament, Rachel and Leah "give" their maids Bilhah and Zilpah to Jacob to bear children for them. This has occasionally been called surrogacy, although issues of consent and the lack of medical intervention to conceive make it surrogacy only in the very loosest sense. Genesis 30:1-13. 
she is not biologically related. ${ }^{94}$ The egg and sperm may be donated by two intended parents, by one intended parent and one donor, or by two donors. The genetic relationship between intended parents and child thus may or may not be present- but no genetic relationship exists between surrogate and child.

Surrogacy, like most other forms of ART, is entirely regulated by state law. There is considerable variation in how state law views surrogacy contracts. This lack of uniformity opens the field to manipulation. Surrogacy agencies may use the internet to coordinate arrangements between intended parents and surrogates in other states-sometimes all in different states than the surrogacy agency itself. ${ }^{95}$ Indeed, surrogacy agencies sometimes trumpet their locations and the accompanying favorable laws regulating surrogacy as compared to other jurisdictions. For example, one surrogacy agency called Family Formation explains on its website, "All of our gestational carriers reside in California, so we are able to utilize California as our forum state. This allows us to benefit from favorable laws concerning who may be declared the parents of the child and enforceability of gestational surrogacy contracts." $" 96$ In the rare instances in which a surrogacy agreement is challenged, ${ }^{97}$ therefore, courts may face the recent example of a New Jersey man who contracted the services of a gestational surrogate in South Carolina as arranged by an attorney located in Indiana. ${ }^{98}$

There are two issues that state laws regulating surrogacy may address. First, states may regulate the practice of surrogacy agreements by explicitly permitting, prohibiting, or regulating agreements through substantive requirements. Second, states also speak to determinations of legal parentage in the context of surrogacy. Of the states that speak to surrogacy at all, only a handful specifically permit surrogacy. Florida and Utah allow even "commercial" surrogacy agreements, meaning that fees are paid to the surrogate above and beyond expenses associated with her pregnancy. ${ }^{99}$ Other states such as Nebraska, Nevada, and Washington, permit only "uncompensated" surrogacy agreements, in which expenses of the surrogate

94. Erin Y. Hisano, Comment, Gestational Surrogacy Maternity Disputes: Refocusing on the Child, 15 LEWIS \& CLARK L. REV. 517, 524 (2011) ("One study reported that the practice of gestational surrogacy in the United States increased from less than $5 \%$ of all surrogate arrangements in 1988 to more than $50 \%$ as of $1994 . ")$.

95. See DiFonzo \& Stern, supra note 92 , at 362.

96. Katherine Drabiak et al., Ethics, Law and Commercial Surrogacy: A Call for Uniformity, $35 \mathrm{~J}$. L. MED. \& ETHICS 300,306 (2007).

97. One scholar identified the rate of contested surrogacy agreements as one percent of all surrogacy agreements. Hollandsworth, supra note 9, at 186 (citing Lori B. Andrews, Surrogate Motherhood: The Challenge for Feminists, 16 LAW MED. \& HEALTH CaRE 72, 74 (1988)). The underlying data is thus over two decades old, and was measured at a time when surrogacy was less commonly used.

98. Drabiak et al., supra note 96 , at 301 .

99. Karen Busby \& Delaney Vun, Revisiting The Handmaid's Tale: Feminist Theory Meets Empirical Research on Surrogate Mothers 13 (2009) (unpublished manuscript), available at http://claradoc.gpa.free.fr/doc/329.pdf. 
may be paid but no other fees are permitted. ${ }^{100}$ Some of the states permitting surrogacy agreements impose substantive requirements on the arrangement: for example, in New Hampshire an intended mother must be "medically determined to be physiologically unable to bear a child without risk to her health or to the child's health," at least one of the intended parents must be a biological parent of the resulting child, and only the intended mother or the surrogate may provide the egg for the surrogate. ${ }^{101}$ In addition, in New Hampshire a surrogacy agreement must include a waiting period of 72 hours during which a surrogate may rescind her agreement. ${ }^{102}$ Several states enforce surrogacy agreements only if the intended parents are a married heterosexual couple. ${ }^{103}$ Additionally, several states specify that only gestational surrogacy agreements-not genetic surrogates-will be enforced. ${ }^{104}$

By contrast, several states prohibit surrogacy agreements entirely. ${ }^{105} \mathrm{~A}$ number of states refuse to enforce commercial surrogacy agreements. ${ }^{106}$ Louisiana, Michigan, New York, and Washington further specify that commercial surrogacy contracts are against public policy. ${ }^{107}$ Kentucky, Michigan, New York, Utah, and Washington also criminalize payment of a fee for surrogacy.

Answers similarly vary as to determination of legal parentage of the children of surrogates. In most states that prohibit surrogacy agreements, the surrogate is deemed to be the legal mother of the child. ${ }^{108}$ Michigan determines parentage by assessing what would be in the best interest of the child. ${ }^{109}$ Even in states that permit at least some surrogacy agreements, assignment of legal parentage varies. Some states determine legal parentage by biological relationship: Ohio, the state of residence of a surrogate recently used by the actors Sarah Jessica Parker and Matthew Broderick, requires that birth certificates be issued in the name of the genetic parents of a child even if a surrogate is used. ${ }^{110} \mathrm{~A}$ few states, including Arkansas ${ }^{111}$ and Illinois, ${ }^{112}$ provide

100. See Joslin, supra note 44 , at 607.

101. See N.H. REV. STAT. ANN. \& 168-B:17 (2012).

102. Id. $\$ 168-\mathrm{B}: 25$ (IV).

103. See Joslin, supra note 44, at 607 n. 237 (listing Florida, Nevada, New Hampshire, Texas, Utah, and Virginia).

104. See, e.g., 750 ILl. COMP. STAT. ANN. 47/10 (West 1999 \& Supp. 2007); TEX. FaM. CODE ANN. § 160.754(c) (West 2011); UTAH CODE ANN. § 78B-15-801(7) (West 2011).

105. Joslin, supra note 44, at 607 \& n.238 (listing Arizona, Indiana, Louisiana, Michigan, New York, North Dakota, and the District of Columbia).

106. IND. Code ANN. \$31-20-1-1 (West 2011); KY. REv. STAt. ANN. \$199.590 (West 2010); LA. REV. STAT. ANN. § 9:2713 (2012); NEB. REV. STAT. § 25-21, 200 (2010); WASH. REV. CODE ANN. § 26.26.240 (West 2012).

107. LSA- R.S. 9:2713 (1987); MICH. COMP. LAWS ANN. $\$ 722.855$ (West 2011); N.Y. DOM. REL. LAW $\$ 122$ (McKinney 2012); WASH. REV. CODE. ANN $\$ 26.26 .240$ (West 2012)

108. See, e.g., ARIZ. REV. STAT. ANN. $\$ 25-218$ (B) ("A surrogate is the legal mother of a child born as a result of a surrogate parentage contract and is entitled to custody of that child.").

109. MiCH. COMP. LAWS ANN. $\S 722.861$ (West 2011 ).

110. Busby \& Vun, supra note 99 , at 13 \& n. 40.

111. ARK. CODE ANN. § 9-10-201 (2011). 
that intended parents will be deemed the legal parents only in the case of gestational surrogacy. Virginia specifies that at birth the surrogate is the legal mother of the child unless the intended mother is also the biological mother of the child. ${ }^{113} \mathrm{~A}$ handful of states will declare the intended parents to be the legal parents if they meet substantive standards specified in statute, often the same standard used to approve adoptive parents. ${ }^{114}$

While there is considerable variance in how surrogacy agreements are treated, there are nonetheless a few salient points to be drawn. First, in almost all states, parentage of children born to surrogates is established only at or after birth. Second, most states do not provide statutory guidance as to surrogate parentage. In those states, if a surrogacy agreement is contested, judges will look to existing parentage standards-primarily the marital presumption and biology - to determine parentage. Finally, a number of states that do speak directly to surrogacy treat genetic surrogates and gestational surrogates differently, and are much more likely to enforce a surrogacy agreement if the surrogate is gestational only.

\section{Pregnancy, Parentage, and Time}

Imagine a time continuum marked by two events: the conception of a fetus and the birth of the resulting child. A woman's intent to opt out of being declared the legal parent of a child is recognized by the law if it happens in the first segment, pre-conception: women can donate eggs and relinquish their parental status and rights. And after birth, women can relinquish their parental status through adoption. But within the middle segment-the time of pregnancy-a woman cannot opt out with finality; she must instead renew her intent after birth. Examining justifications for this temporary period of nonintent raises troubling questions of motherhood and competence.

As a threshold matter, the question of whether one is declared the legal parent of a child is different from whether one carries a pregnancy to term. If a pregnant woman does not wish to be the legal mother of her fetus, in other words, she does have the ability to avoid motherhood by having an abortion. If she is willing to carry the pregnancy to term but does not wish to be the legal mother of the child, however, she may not be able to relinquish parental status until after the birth. The law assumes that if a woman gives birth, she wants to be the mother of that child - in contrast, as will be discussed below, to the default assumption that men do not want to be fathers, even if they are genetically related to a child.

112. 750 ILL. COMP. STAT. ANN. 47/35 (West 2012)

113. VA. CODE ANN. \& 20-158(E) (West 2011).

114. See UTAH CODE ANN. \& 78B-15-803 (requiring that intended parents be subject to a home study and "meet the standards of fitness applicable to adoptive parents"); VA. CODE ANN. § 20-160 (West 2011) (same). 
There are several justifications for refusing to allow pregnant women to give up legal parentage of the child to which they later give birth. One common criticism is that surrogates are vulnerable to economic coercion: surrogacy commodifies reproductive labor and "creates a breeder class of poor women" selling their bodies to more economically powerful women. ${ }^{15}$ Margaret Radin, for example, argues that to treat personal attributes such as family, love, and sexuality "as monetizable or completely detached from the person ... is to do violence to our deepest understanding of what it is to be human."

Scholars such as Martha Ertman and Katharine Silbaugh have argued that the anticommodification argument is essentialist and overlooks the economic benefits to both "sellers" and otherwise marginalized "buyers" of reproductive services. ${ }^{117}$ To view surrogacy as dehumanizing the surrogate, in other words, assumes that reproductive labor is central to a woman's life and identity in a way that other forms of labor are not.

Furthermore, although information from women who have served as surrogates is scant, available data surveying surrogate mothers and the intended parents with whom they contracted paints a more complex picture than the commodification argument portrays. Surveys indicate that an economic inequality exists between intended parents and surrogates: intended parents are typically older than the surrogates, are more highly educated, and are more financially well-off-but surrogates are not so economically underprivileged that surrogacy appears to be their only source of income. ${ }^{118}$ The surrogate mothers, moreover, reported that money was "infrequently even the main reason" for their interest in surrogacy, and gave "desire to help a childless couple" as the "prime motive" behind their work as surrogates. 119

Another argument concerning the significance of pregnancy turns on a hypothesized bonding between woman and fetus during pregnancy. The

115. Pamela Laufer-Ukeles, Approaching Surrogate Motherhood: Reconsidering Difference, 26 VT. L. REV. 407, 424 (2002). See also Elisabeth M. Landes \& Richard A. Posner, The Economics of the Baby Shortage, 7 J. LEG. STUD. 323 (1978) (famously arguing for an open market in adoptions). But see Ertman, supra note 62, at 7 ("Academic hand-wringing about whether selling parenthood would be a good thing implies that we do not already buy and sell it. But the practice is alive and well in various guises, direct and indirect.").

116. Margaret Jane Radin, Contested Commodities: The Trouble with Trade in SeX, Children, Body Parts, and Other Things 56 (1996); see also Carol Pateman, The Sexual CONTRACT 206-18 (1988); Margaret Jane Radin, Market-Inalienability, 100 HARV. L. REV. 1849, 1903 (1987) ("My central hypothesis is that market-inalienability is grounded in noncommodification of things important to personhood.").

117. See Ertman, supra note 62, at 49 (identifying single women and lesbian couples as beneficiaries of a reproductive market); Katharine Silbaugh, Commodification of Women's Household Labor, 9 YALE J.L. \& FEMINISM 81, 85 (1997).

118. Busby \& Vun, supra note 99 , at $19-20$.

119. Id. at 26-28. Such inequalities may be magnified, however, in the context of the growing international market for surrogates, in which American intended parents contract with a woman in another country, often India, to serve as gestational surrogate. See Lisa C. Ikemoto, Reproductive Tourism: Equality Concerns in the Global Market for Fertility Services, 27 LAW \& INEQ. 277 (2009); Margaret Ryznar, International Commercial Surrogacy and its Parties, 43 J. MARSHALL L. REV. 1009 (2010). 
purported harm of breaking this bond can be one of two possibilities. First, there is a theory that it will harm the child to be removed from the loving care of the gestational mother, who will provide better care than an alternative parent. ${ }^{120}$ As described above, however, studies indicate that adopted children receive the same level of care and experience the same emotionally significant bonding with adoptive parents as children raised by their biological parents, so a concern focused on the children's care is unconvincing.

Second, however, is the more common argument that not only will pregnant women be emotionally harmed by separation from the child they gave birth to, but that they will not be able to predict that emotional harm. Katharine Bartlett described belief, in the context of custody determinations, in a "mystical bond" developed during pregnancy and childbirth that is "inevitable and more powerful than any woman can realize in advance." 121

Although the Supreme Court has not spoken directly to surrogacy, its opinions distinguishing biological mothers from biological fathers provide evidence that at least some Justices agree that pregnancy creates a powerful bond between woman and fetus. For example, in his dissent from Stanley $v$. Illinois, Chief Justice Burger wrote, "I believe that a State is fully justified in concluding, on the basis of common human experience, that the biological role of the mother in carrying and nursing an infant creates stronger bonds between her and the child than the bonds resulting from the male's often casual encounter." ${ }^{122}$ Other courts have explicitly relied upon such reasoning in the context of surrogacy. In the famous Baby $M$ case, in which the New Jersey Supreme Court refused to enforce a surrogacy contract and declared the genetic surrogate and intended father to be the two legal parents of the child, the court declared that "Under the [surrogacy] contract, the natural mother is irrevocably committed before she knows the strength of her bond with her child. She never makes a totally voluntary, informed decision, for quite clearly any decision prior to the baby's birth is, in the most important sense, uninformed." 123 Over a decade later, a pair of intended parents and a gestational surrogate-the intended mother's sister - petitioned the New Jersey courts for a prebirth order establishing that the intended parents were the legal parents. The Superior Court declined, explaining that even though the surrogate was not the biological mother, "[a] bond is created between a gestational mother and the baby she carries in her womb for nine months." 124 Although the surrogate before the court was unlikely to change her mind, the court acknowledged, a

120. See Hill, supra note 88 , at $394-405$.

121. Bartlett, supra note 9 , at 333 .

122. Stanley v. Illinois, 405 U.S. 645, 665 (1972) (Burger, C.J., dissenting).

123. In re Baby M, 537 A.2d 1227, 1248 (N.J. 1988).

124. A.H.W. v. G.H.B., 772 A.2d 948, 953 (N.J. Super. Ct. Ch. Div. 2000). 
hypothetical future surrogate who had not had a child before "will not be able to predict what her feelings will be towards the child she bears." 125

Surveys of surrogate mothers, however, do not support these beliefs. One study of sixty-one British surrogates found that "detachment is reported early and maintained throughout the pregnancy." 26 The Busby and Vun review of studies examining surrogates concluded that "most surrogate mothers did not think of the fetus as theirs; they considered it to be for the commissioning parents from the beginning of the process and demonstrated lower attachment during pregnancy than other pregnant women."127 Busby and Vun concluded that "[t]he empirical research demonstrates that surrogate mothers are not subject to emotional volatility during pregnancy and that they do not become pre-natally attached to the fetus." 128

One explanation for the lack of attachment between surrogate and fetus is the most salient difference between surrogacy and adoption: a surrogate mother intends the entire time to give the baby up. As John Lawrence Hill explained,

If the postrelinquishment experience of birth mothers is at all related to their previous feelings regarding the child, then it is possible that women who do not expect to raise the child may be relatively less affected by relinquishment. This possibility is suggested by one poll of surrogate mothers in which only one in five reported that relinquishment was the most difficult aspect of the arrangement. ${ }^{129}$

One might argue that legal regimes should nonetheless allow surrogates to back out of the surrogacy agreements because the law should prevent the emotional harm to even the small minority of surrogates who have second thoughts during their pregnancy. The very existence of a strong regime enforcing surrogacy agreements, however, may actually work to prevent any harm.

If there is any truth to the notion that the feelings of the gestational host toward the child are influenced by her expectation of raising the child, then the surrogate may develop proprietary feelings toward the child because she retains the possibility of challenging the claims of the intended parents. However, if this prospect is not open to her, the gestational host will be less likely to entertain such sentiments toward the child. ${ }^{130}$

125. Id.

126. Busby \& Vun, supra note 99 , at 37 (internal quotations omitted).

127. Id.

128. Id. at 40

129. Hill, supra note 88 , at 406 .

130. Id. at 417 . 
In addition, although the potential emotional harm to the surrogate is a frequent topic of discussion in debates about surrogacy, the potential emotional harm to the intended parents receives much less attention. The intended parents plan for a child at least as long as parents who reproduce through traditional means-even longer, to the extent that finding gamete donors and a surrogate and then waiting through the preparation and medical procedures is a longer period of "trying to conceive" than traditional sexual reproduction. Throughout this time, intended parents invest financially in preparing for their child's arrival, plan to take maternity or paternity leave, and generally ready for their child's birth as any other parents would. Intended parents often support the surrogate not only financially through covering the costs of her pregnancy, but also participate in the pregnancy by attending doctor's visits with the surrogate. In many ways, intended parents act akin to a biological father who is no longer partnered with the biological mother, in that they feel a clear tie to the developing fetus, go through the practical and emotional process of preparing to be a parent, but do not go through the pregnancy themselves. The loss of the child for whom they have waited and anticipated would be just as traumatic as a father whose partner lost a wanted pregnancy.

In the context of abortion rights, Jennifer Hendricks stated that antiabortion arguments "are based on traditional, paternalistic views that women should be protected from poor decisions, or from coercion, by eliminating their choices, rather than by informing and empowering their decisions." "131 Similar views protecting pregnant women from poor advance decision-making appears to motivate treatment of surrogates' intent. The contrast between rhetoric discussing the "harm" to surrogates and surrogacy regulation discussed above highlights the problem: if pregnancy itself creates the harm of surrogacy, why do many states allow gestational, but not genetic, surrogacy? It seems unlikely that a gestational surrogate can detach herself from the fetus where a genetic surrogate cannot.

Indeed, the different intuitions regarding gestational versus genetic surrogates seem premised on some of the same assumptions that underlie the evolutionary biology arguments, outlined above in section I.B, that biological parents do a better job of parenting than parents who are not biologically related to their children. As June Carbone and Naomi Cahn have exhaustively detailed, however, this argument is unconvincing-and moreover, existing parentage regimes have rejected biology as a necessary condition of parentage. The perceived difference between gestational and genetic surrogacy thus appears to rest on a conclusory instinct that a genetic surrogate is giving up "her" child, whereas a gestational surrogate is not.

131. Jennifer S. Hendricks, Body and Soul: Equality, Pregnancy, and the Unitary Right to Abortion, 45 HARV. C.R.-C.L. L. REV. 329, 336-37 (2010). 
A woman is free to donate an egg to another woman and voluntarily opt out of her parentage status to any resulting child. A gestational surrogate is in several jurisdictions able to carry a fetus to term and voluntarily opt out of her parentage status to that child. Indeed, at least one writer has argued that not to do so, when men may use biological evidence to rebut paternity, would violate the Equal Protection Clause. ${ }^{132}$ If a woman does both, however-if she intends to donate her egg and carry an embryo created with that egg to term, to be the legal child of an intended parent or parents - a significant number of states distrust her intent. The reason appears to be a well-meaning but unsupported belief that women's advance intent before pregnancy is uninformed and ultimately incorrect. This conviction, however, rests upon a stereotype of women's natural mothering instincts. Crediting the intent of surrogates by utilizing intent as one tool in a parentage regime will thus not only facilitate the planning of intended parents, but also address one gendered facet of parentage determinations.

The next section turns to the other side of the gender divide and assesses how incorporating intent into statutory parentage regimes would affect the parental rights of unwed fathers.

\section{B. Gender}

Parental intent is treated differently depending on whether the intent belongs to a man or a woman. Fatherhood, as discussed earlier, may be established through the marital presumption, or may be imposed upon the biological father if the mother seeks child support from him. ${ }^{133}$ Biological connection alone, however, is not enough to establish fatherhood. In a famous line of "unwed father" cases, the Supreme Court established that "[d]e facto, if not de jure, it is the gestational mother who controls whether a biological father. . is able to establish a relationship with the child and thereby secure parental rights." 134 The Supreme Court is thus at least minimally concerned with the timing of intent to be a father, but only post-birth intent. The inconsistent treatment of unwed fathers thus illustrates two points about intent: first, that existing recognition of intent only happens after birth, where prebirth intent has the potential to have the most effect in parentage determinations; and second, that intent is currently acknowledged only where it fits existing gender stereotypes.

132. Emily Stark, Born to No Mother: In re Roberto D.B. and Equal Protection for Gestational Surrogates Rebutting Maternity, 16 AM. U. J. GENDER, SOC. POL'Y \& L. 283, 294 (2007-2008).

133. Contrasting fathers to lesbian mothers, Susan Dalton argued that men can more easily become social fathers to nonbiological children than women can become social mothers to the biological children of a same-sex partner. See Dalton, supra note 58.

134. Baker, supra note 35 , at 46. 


\section{Fathers and Time}

In a line of cases beginning with the 1972 case Stanley $v$. Illinois, ${ }^{135}$ the Supreme Court has established that unwed biological fathers must create a substantial relationship with their children before they have constitutionally recognized parental rights. Some of the Court's explanations as to why unmarried fathers must also create a relationship with the child-a requirement that unwed mothers need not meet-focus on the importance of proving fatherhood through actions maintained throughout childhood. The younger the child, in other words, the less of a father the Court sees.

For example, in Caban v. Mohammed, the Court was faced with a biological father seeking to prevent the adoption of the child by the biological mother's husband. ${ }^{136}$ The unwed father prevailed in his argument, but the Court's explanation placed considerable importance on how much time had elapsed since the child's birth: "Even if unwed mothers as a class were closer than unwed fathers to their newborn infants, this generalization concerning parent-child relations would become less acceptable as a basis for legislative distinctions as the age of the child increased." ${ }^{137}$ The Court explicitly rejected a blanket gender-based distinction as justified by a "universal difference between maternal and paternal relations at every phase of a child's development." The rejection of a gender-based distinction, however, was not untempered, as Justice Powell suggested that a distinction between unwed mothers and fathers could be legitimate when the child was very young - particularly if finding and identifying the father would be an impediment to a child's adoption at a very young age - as opposed to when the child was older and the "father has established a substantial relationship with the child and has admitted his paternity."139

A similar reasoning focusing on post-birth action is present in cases dealing with the citizenship status of children born to one American citizen parent. In 2000, the Supreme Court decided Nguyen $v$. INS, in which the child of an American citizen father and a Vietnamese mother faced deportation after being convicted of sexual assault on a child. ${ }^{140}$ Federal law provided that if a child was born abroad and out of wedlock to an American citizen mother, the child was an American citizen. ${ }^{141}$ If the American citizen parent was the father, however, a series of substantive requirements applied, including that the

135. 405 U.S. $645,646(1972)$.

136. 441 U.S. 380 (1979).

137. Id. at 389 .

138. Id.

139. Id at 393 .

140. 533 U.S. 53 (2000).

141. Id. at 60 (noting that the mother must have been physically in the United States or an outlying possession for at least one continuous year). 
father's paternity had to be acknowledged or adjudicated. ${ }^{142}$ The Court held that the statute's gender-based classification did not violate equal protection, even under heightened scrutiny. The Court justified the distinction according to gender with the "different relationships" 143 of mother and father to the child at birth, which the Court concluded served two important governmental interests: first, establishing that a parent-child relationship did actually exist; and second, guaranteeing "that the child and the citizen parent have some demonstrated opportunity or potential to develop ... a relationship ... that consists of the real, everyday ties that provide a connection between child and citizen parent and, in turn, the United States." Justice Kennedy's opinion for the Court argued that the difference between mothers and fathers served both purposes. One thread of argument resembled the argument in Stanley that for practical purposes it was legitimate to focus on the mother at birth because she could be more readily identified: "[I]t is not always certain that a father will know that a child was conceived, nor is it always clear that even the mother will be sure of the father's identity." 145 Justice Kennedy argued that this meant that the government could constitutionally require "some opportunity for a tie between citizen father and foreign born child which is a reasonable substitute for the opportunity manifest between mother and child at the time of birth." 146

The Court's focus on the moment of birth as a definitive point in time regarding both identification of parents and the creation of a parent-child relationship bears specifically upon the timing of parental intent, and has not received much criticism or attention. The next section explores the constitutional arguments about parentage, which further illuminate the interaction of time and parental status.

\section{Constitutional Dimensions}

Constitutional arguments regarding parental rights have primarily taken two forms. First, there is a robust proposal that the right to privacy that encompasses the choice not to procreate also includes a choice to procreate. For example, John A. Robertson has argued that although only "avoidance of procreation" has received specific doctrinal protection, "[i]n dicta,... the Supreme Court on numerous occasions has recognized a married couple's right to procreate in language broad enough to encompass coital, and most noncoital, forms of reproduction." 147

142. Id. at 59 .

143. Id. at 68 .

144. Id. at 64-65.

145. Id. at 65 .

146. Id. at 66 .

147. John A. Robertson, Embryos, Families, and Procreative Liberty: The Legal Structure of the New Reproduction, 59 S. CAL. L. REV. 939, 955, 958 (1986); see also Skinner v. Oklahoma, 316 U.S. 535,541 (1942) (referring to procreation as a "basic liberty"). 
Second, a handful of plaintiffs have made equal protection arguments in the context of surrogacy. ${ }^{148}$ These arguments discuss the different treatment of male and female parentage, but focus on mothers and their ability to present biological evidence, either to prove or to disclaim maternity. The disputes arose from the common availability of a procedure by which men could present biological evidence either showing that they were the biological father of a child, and seeking to be recognized as the legal father; or showing that they were not biologically related to the child, and thus disestablishing their paternity. Such determinations were traditionally, for obvious reasons, only made in relation to fathers. In the context of surrogacy, however, pregnancy and biological relationship can be split, and several women involved in surrogacy agreements argued that they should have the same ability as potential fathers to prove or disprove relationships.

The deeper gender difference underlying unwed father cases, however, is the stereotype that men are unwilling and ill-equipped to take on the responsibility of caring for children. ${ }^{149}$ Such a stereotype has been implied in Supreme Court opinions. In Stanley v. Illinois, for example, Chief Justice Burger's dissent notes that “[c]enturies of human experience buttress this view of the realities of human conditions and suggest that unwed mothers of illegitimate children are generally more dependable protectors of their children than are unwed fathers." 150

One could ask, therefore, whether surrogacy cases might, by splitting biology and intended parentage, demonstrate further inequality in how easily men and women can opt into parenting. It is hard to isolate gender, however, in the context of surrogacy. First, as Busby and Vun discovered, contested surrogacy agreements are generally from the 1980 s and $1990 \mathrm{~s}$, and involve genetic surrogacy rather than gestational surrogacy. ${ }^{151}$ The Baby $M$ case is typical: the child at issue was the biological child of the intended father and the

148. J.R. v. Utah, 261 F. Supp. 2d 1268, 1294 (D. Utah 2002); Soos v. Superior Court, 897 P.2d 1356, 1361 (Ariz. Ct. App. 1995).

149. Nancy E. Dowd, From Genes, Marriage and Money to Nurture: Redefining Fatherhood, 10 CARDOZO WOMEN'S L.J. 132, 136 (2003) ("One gender challenge is the very definition of masculinity in anti-care, anti-nurture terms, linked to the promotion of homophobia in the definition of masculinity."); Nancy E. Dowd, Law, Culture, and Family: The Transformative Power of Culture and the Limits of Law, 78 CHI.-KENT L. REV. 785, 792 (2003); Katherine T. Bartlett, Saving the Family from the Reformers, 31 U.C. DAVIS L. REV. 809, 837-38 (1998) ("On average, mothers are available for their children twice as much as fathers and spend three times as much time interacting with their children (as opposed to passive babysitting)."); cf. Clifford J. Rosky, Like Father, Like Son: Homosexuality, Parenthood, and the Gender of Homophobia, 20 YALE J. L. \& FEMINISM 257, 265-66 (2009) (noting that mothers are more likely to be the primary caretaker ).

150. Stanley v. Illinois, 405 U.S. 645, 666, (1972); see also Laura Oren, The Paradox of Unmarried Fathers and the Constitution: Biology "Plus" Defines Relationships; Biology Alone Safeguards the Public Fisc, 11 WM. \& MARY J. WOMEN \& L. 47, 53 (2004-2005) (arguing that Burger "implied that without marriage, adoption, or some other legal undertaking, men were per se reluctant fathers").

151. Busby \& Vun, supra note 99, at 14; see also Pamela Laufer-Ukeles, Gestation: Work for Hire or the Essence of Motherhood?: A Comparative Legal Analysis, 9 DUKE J. GENDER L. \& POL'Y 91, 98 (2002). 
surrogate. Parentage was resolved by deeming the biological parents to be the legal parents, and then custody was decided between the two in a similar manner as if they were divorced parents fighting over custody. ${ }^{152}$ Cases arising because a surrogate reneges on the agreement, therefore, do not isolate gender from biological connection.

Another context in which both male and female intended parents seek to establish parentage of a child to whom they are not biologically related occurs when the intended parents are a same-sex couple. In many such cases, one of the same-sex partners is the biological parent of a child-born either through surrogacy or artificial insemination-and the other partner seeks to be recognized as the second legal parent. Such cases illuminate gender stereotypes in parenting, but primarily in contrasting same-sex couples to heterosexual couples. As Susan Dalton explained, "the courts continually assume that marriage is the only appropriate venue for family construction and that nature imposes restrictions on the configuration of the parenting dyad," "I53 and by "narrowly constructing parenthood in ways that preserve traditional constructions of motherhood and family."154 ART thus provides more information about stereotypes of homosexual versus heterosexual parenting than purely male versus female parenting. ${ }^{155}$

Examining arguments in the unwed father cases, however, help to uncover the significance - at at least in the eyes of current family law - of the moment of birth in establishing parentage. As discussed above in the context of unwed fathers, the Supreme Court focuses on the moment of birth as determinative for a few reasons: easy identification of a parent, efficient identification of a financially responsible party, and a belief that mothers are more emotionally bonded with newborns than fathers. ${ }^{156}$

Even if these reasons are valid after birth, however, they are not equally valid throughout time. It is true, whether the concern is the paternity of a child of unwed parents or the citizenship status of that child, that the easiest person to identify as a parent will be the woman physically giving birth to the child. As discussed above, however, the development of surrogacy has decoupled pregnancy and biological relationship. While current reproductive technologies ensure that at least one person is present at birth, therefore, the woman giving birth is not necessarily the parent as family and immigration law contemplate it.

152. In re Baby $M, 537$ A.2d 1227 (1988).

153. Dalton, supra note 58 , at 290.

154. Id. at 293 .

155. See Jessica Hawkins, My Two Dads: Challenging Gender Stereotypes in Applying California's Recent Supreme Court Cases to Gay Couples, 41 FAM. L. Q. 623 (2007) (arguing that UPA should be applied in the same way to female and male same-sex couples); Rosky, supra note 149, at 279-94 (comparing treatment of gay fathers and lesbian mothers).

156. Stanley v. Illinois, 405 U.S. 645, 665 (1972) (Burger, C.J., dissenting). 
In the context of unwed fathers, the Court seems concerned with development of a significant relationship between father and child. As Jennifer Hendricks summarized, the Court held "that the father is differently situated at the time of birth and that he remains differently situated unless and until he establishes a caretaking relationship with the child." 157 An intended father through surrogacy, however, can signal his clear intentions to be present and involved in his child's life, committing to the relationship that will trigger constitutional parental rights or transmit American values and culture. To the extent that unwed fathers are held financially responsible for their children, moreover, identifying intended parents as legal parents would also provide financial protection that is currently lacking should the intended parent die before the child's birth. ${ }^{158}$ Recognition of intended parents as legal parents would thus address both the equal protection concerns focused on the gender of the parents ${ }^{159}$ and financial protection for the resulting child.

\section{PREBIRTH PARENTAGE ORDERS}

As discussed above, intent is currently treated inconsistently by family courts faced with difficult factual problems arising out of ART. Greater incorporation of intent to be a parent as a parentage rule would resolve this inconsistent treatment as well as begin to address the broader problem that parentage is currently only determined after birth, where prebirth resolutions would establish legal parentage and all of the attendant protections for children who are currently left unaddressed by existing law. I propose the use of prebirth parentage orders as an initial means of incorporating intent into parentage rules. A prebirth order directs who the legal parent or parents of a future child will be. Most concretely, such an order directs which names will appear on the child's birth certificate, but the order also prevents later challenges to the child's parentage.

Use of prebirth parentage orders would be a significant change from existing law. In state law currently, the trend is firmly against prebirth determination of parentage. Only a handful of states have entertained prebirth determinations in any form. California state law, for example, specifically allows actions determining parentage to be brought before the birth of the child, but specifies that enforcement of any order will be stayed until after the

157. Jennifer S. Hendricks, Essentially a Mother, 13 WM. \& MARY J. WOMEN \& L. 429, 441 (2007).

158. See Courtney G. Joslin, Protecting Children (?): Marriage, Gender, and Assisted Reproductive Technology, 83 S. CAL. L. REV. 1177 (2010).

159. See Marjorie Maguire Shultz, Legislative Regulation of Surrogacy and Reproductive Technology, 28 U.S.F. L. REV. 613, 617-18 (1994) ("In my judgment, equitable gender opportunity requires legal approaches that offset biologically imposed limits on men's involvement in reproduction and childrearing, just as the law should offset women's biologically imposed disabilities in the employment market."). 
child's birth. ${ }^{160}$ The Massachusetts Supreme Court held in 2001 that Massachusetts probate and family courts had the authority to issue a prebirth parentage declaration, although by the time the issue reached the court the child had been born. ${ }^{161}$ By contrast, a number of states-generally those states that also explicitly prohibit surrogacy in state law-also expressly prohibit any action determining the parentage of a child until after the child's birth. ${ }^{162}$

A small number of states that do not expressly permit prebirth parentage orders do allow or even require pre-conception judicial approval of surrogacy agreements. ${ }^{163}$ Such requirements thus parallel some of the mechanism of a prebirth parentage order, in that all of the parties to the agreement are part of a formal court proceeding before a pregnancy is begun. In such states, approval of the surrogacy agreement could be easily combined with issuance of a prebirth parentage order.

\section{A. Mechanism}

A prebirth parentage order would add one step between reaching a surrogacy agreement and the fertility clinic's taking steps to begin the surrogate's pregnancy. Surrogacy agreements, depending on the jurisdiction, currently encompass multiple topics, including economic compensation to the surrogate, storage arrangements of embryos not implanted in the first attempts at pregnancy, and other issues arising out of the surrogacy process itself. Prebirth parentage orders, by contrast, address one issue only: the legal parentage of the resulting child. ${ }^{164}$

After a surrogacy agreement is agreed to, the intended parents would seek a prebirth parentage order from the family court in the jurisdiction in which the surrogate expects to give birth (in most circumstances, the jurisdiction in which she resides). All potential parents as identified by state law, however, would be party to the proceedings. For example, in the context of gestational surrogacy, potential parties would include the intended parent or parents, egg donor, sperm donor, gestational surrogate, and the surrogate's husband.

Notably, not every one of these parties would be involved in every single case. For example, egg and sperm donors would typically not need to provide a

160. CAL. FAM. CODE $\S 7633$ (West 2006); Maguire Shultz, supra note 162 at 643-44.

161. Culliton v. Beth Israel Deaconess Med. Ctr., 756 N.E. 2d 1133, 1138 (Mass. 2001). The intended parents filed a complaint seeking a declaration of their legal parentage as well as an order directing the hospital to list the intended parents as parents on the child's birth certificate. Id. at 1136 . Such orders would be available only where the intended parents were also the biological parents of the child and the surrogate had no objection to the order.

162. See Mary Patricia Byrn \& Steven H. Snyder, The Use of Prebirth Parentage Orders in Surrogacy Proceedings, 39 FAM. L.Q. 633, 642 (2005).

163. Id. at 651 .

164. Pregnancies involving ART often involve multiple births such as twins or triplets, and prebirth parentage orders would thus be drafted to apply to the child or children produced by a single pregnancy. For ease of reading in this section, however, I will use "child" exclusively. 
second statement waiving parental status, as such donations are generally made in a clinical context and already involve standard waivers of parentage. To the extent that such waivers do not already exist, or the donor might have a functional claim as in $K M$ v. $E G$, the donor would participate in the prebirth parentage order. Similarly, I propose that prebirth parentage orders be available to both gestational and genetic surrogates, for example, which could remove egg donor from the list. Key, however, is that every potential parent under the state law of the relevant jurisdiction is included in the proceeding.

The main purpose of the order would be to determine with finality who the legal parent or parents of the future child will be. There is thus an important time component to the order, making clear both the start and end dates of its applicability.

Examining the start of the order, prebirth parentage declarations should be based on agreements entered into before conception of the child occurs. In the context of assisted reproduction, conception is an imprecise term, and could be identified at a minimum of two points: first, when sperm and egg meet; second, when the resulting embryo implants in a woman's uterus. ${ }^{165}$ The difference is important because multiple embryos are typically created in pursuit of a single pregnancy. Extra embryos are often stored by fertility clinics for years, both to use if the first pregnancy is not successfully carried to term or if intended parents later desire a second pregnancy. Courts have already been faced with biological parents who disagree as to later use of stored embryos. ${ }^{166}$ Prebirth parentage orders that would apply to embryos, therefore, introduce obvious problems in that an order could be issued years before the embryo was ever implanted and brought to term. Similarly, if an order applied to every embryo created, one order could potentially apply to dozens of future pregnancies and children. Each prebirth parentage order should thus specify that it applies to one pregnancy, the beginning of which is defined by one or more embryos simultaneously implanting in the surrogate's uterus. Thus if multiple embryos successfully implant, one order will settle the parentage of both twins.

Similarly, orders must also be specific as to duration of the agreement, specifying an end date to the order's efficacy. If the intent to become a legal parent was indefinite, for example, one agreement could in theory be used decades after its execution if it took that long for a surrogate's successful pregnancy to be begun and carried to term. Instead, agreements should apply to one pregnancy carried to term, and should have a time limit: if a pregnancy has not commenced within one year, the agreement must be re-executed to be the basis for a prebirth parentage order.

165. See Dara E. Purvis, Of Financial Rights of Assisted Reproductive Technology Non-Marital Children and Back-up Plans, 83 S. CAL. L. REV. POSTSCRIPT (Jan. 2011).

166. See id.; see also, e.g., Litowitz v. Litowitz, 48 P.3d 261, 262 (Wash. 2002). 
As for the content of the court's involvement, the approach that most incorporates the advantages of intent as a parentage regime would be to provide procedural protections for the parties involved, and so long as the court was satisfied that the parties fully understood the consequences of the order, to issue a prebirth parentage order specifying that the intended parents would be the legal parents of the resulting child.

Protections for the decision-making process of the involved parties could incorporate protections that would prevent some of the issues that have given rise to challenged surrogacy agreements in recent years. For example, a Massachusetts court suggested that courts consider factors such as psychological evaluations of all parties involved, whether the parties received legal advice, and whether the surrogate mother had carried at least one pregnancy to term. ${ }^{167}$ Courts could similarly review the surrogacy agreement to ensure that compensation for the surrogacy was not so high that it could be seen as economic coercion. Such conditions could be incorporated into the requirements for securing a prebirth parentage order, rather than used after birth as a factor in considering whether to enforce an existing surrogacy agreement.

Courts considering such an order could also highlight particularly problematic contingencies that private surrogacy agreements often do not address through an inquiry analogous to a plea colloquy. For example, the intended parents could be asked whether they have considered whether their plans would change if they divorce before the child's birth, or whether all the parties have discussed what will happen should prenatal testing reveal abnormalities in the fetus. Because surrogacy agreements are usually drafted by fertility clinics, the focus of such agreements is on the responsibilities of the clinic during the course of the pregnancy rather than potential disputes that would not directly involve the clinic. Prebirth parentage orders would thus prompt or even require the parties to consider potential areas of concern that are currently underserved by surrogacy agreements.

Finally, prebirth parentage orders could incorporate substantive requirements. In California and Massachusetts, for example, the two states that at least theoretically could determine parentage prebirth, courts have specified that such orders would be issued only when the intended parents are also the genetic parents of the child. ${ }^{168}$ As argued above, this article contends that intent alone is a desirable rule both for policy-based and normative reasons, and need not be applied only where another parentage regime such as biology would also apply. Because such substantive restrictions could be incorporated into a court's review before issuing a prebirth parentage order, however, such orders could be employed even in states with such restrictions.

167. See R.R.v. M.H., 689 N.E.2d 790, 797 (1998).

168. See Byrn \& Snyder, supra note 165 , at 645,649 
States could also require prebirth parentage orders to be secured for all surrogacy agreements. Currently, Texas and Utah have adopted provisions of the Uniform Parentage Act that require judicial preauthorization of surrogacy agreements, as well as relatively restrictive substantive requirements, in order for the agreement to be recognized. ${ }^{169}$

\section{B. Legal Effect}

The direct consequence of a prebirth order would be that the names of intended parents should be entered on the child's birth certificate at delivery in the hospital and as subsequently filed with the relevant state agency. ${ }^{170}$ The primary functions of parental status in this context would be first, to establish benefit and intestate inheritance rights of the child should anything happen to the intended parent prebirth, and second, to establish from the moment of birth who the legal parent(s) of the child are.

Significantly, prebirth parentage orders would be final determinations of legal parentage, so long as the proceedings were procedurally fair. Orders would be binding on later contestations of legal parentage, so long as the later contestations involved the same parties. In other words, after the order was issued (whether before or after the child's birth), only two types of challenges could be entertained. First, if something about the proceedings was unjust-for example, a surrogate had not had independent counsel-the the order could be set aside. Second, if a person who should have been part of the proceedings was left out, that person could challenge the order.

Such proceedings would not necessarily reopen the order, and might not even disturb the original order's conclusion. For example, if the spouse of an intended parent was left out of the proceedings and prebirth parentage order, they would likely be able to secure parentage rights through a second-parent adoption of the child after birth, leaving the original order intact. If, by contrast, a surrogate proved that her involvement in the order was improper-if she did not meet substantive requirements such as having brought a previous pregnancy to term, for example ${ }^{171}$ - the result would not necessarily be that the surrogate gained parental status over the child. Rather, the parentage order

169. See TeX. FAM. CODE ANN. §§ 160.751-763; UTAH ANN. CODE $\S \S 78 B-15-101$ (West 2011); see also Byrn \& Snyder, supra note 165 , at 653.

170. Interestingly, there appear to be no reported cases involving a surrogate pregnancy delivered outside of a hospital, such as through a home birth, possibly because home births are discouraged for pregnancies of twins or triplets, which are more frequent in pregnancies begun through IVF. If a surrogate's pregnancy was delivered at home, in any case, the prebirth parentage order would apply to the birth certificate as filed with the state agency; the sole difference would be that it would be filled out and filed by the parents themselves according to state law.

171. New Hampshire currently requires that surrogates have "a documented history of at least one pregnancy and viable delivery," and could build the requirement into securing a prebirth parentage order. N.H. REV. STAT. ANN. § 168-B:17 (2012). 
would be void, and a family court would apply existing regimes, such as those courts already apply in disputes regarding surrogacy agreements.

In the absence of such circumstances, however, the parties to the order would not have a claim to challenge the prebirth parentage order. This would apply whether it was a gestational mother claiming parentage or an intended parent wishing to disclaim parental status - appeals would only be heard if they were based on procedural problems as described above.

\section{Benefits and Objections}

One of the chief problems with potential use of intent as a parentage regime is that intent to be a parent is difficult to express. The use of courtissued orders addresses this concern, by requiring a clear, formalized expression of intent. Although intent as expressed through action or verbal statements might be considered in the case of a parentage dispute, prebirth orders require intent to be clearly manifested in a signed record in order to become dispositive. This is in keeping with model statutes that already provide for some circumstances in which consent to become a parent is expressed in writing. For example, the ABA Model Act specifies that "consent by an individual who intends to be a parent of a child born by assisted reproduction must be in a signed record. ${ }^{172}$

Another advantage to the involvement of a court in issuing prebirth parentage orders is that it avoids some of the problems that arise from a purely contractual model of parentage determination. As mentioned above, surrogacy agreements are generally drafted by the fertility clinic assisting in the surrogacy, and thus naturally focus on potential problems that would affect the clinic, rather than issues that would arise solely between the surrogate and intended parents. Additionally, a purely contractual model introduces complications that are more problematic in the realm of family law: for example, if a party to a surrogacy agreement wanted to back out of the agreement, contractual analysis would likely look to monetary damages as a remedy. Payment of monetary damages by one potential parent to another could easily be characterized as selling a baby, which is prohibited by all fifty states. Contractual models would also potentially allow more detailed agreements based on future contingencies. Married intended parents might sign a surrogacy agreement providing that in the case of divorce before the child's birth, only the wife would be deemed the legal parent of the child. This would in effect excuse the husband from what would otherwise be an unavoidable child support obligation. Public policy strongly supports stability and 
permanency in decisions regarding parentage, and a single pre-conception proceeding serves that goal better than a purely contractual analogy.

Another potential objection to the use of prebirth parentage orders arises from the prebirth recognition of future parental status. It could be argued that recognizing future parental status would strengthen a man's ability to prevent a woman pregnant with his child from terminating that pregnancy.

It is important to note, however, that this would be future parental status, not parental status recognized before a child's birth. The order would direct the names of intended parents to appear on the child's birth certificate and to be identified as parents in the future, not "John Smith is the father, with all accompanying rights and obligations, of fetus A." In this sense, the status of intended parents is the same as that of biological parents during pregnancy; there is an expectation of future parenthood, but not actual parental status and its attendant rights. ${ }^{173}$

Currently, even the undisputed future parent of a fetus does not have the right to intervene in a woman's choice to terminate her pregnancy. The Supreme Court held two decades ago that even requiring notice to the husband of a married woman seeking an abortion was an unconstitutional undue burden on the woman's privacy right to an abortion. ${ }^{174}$ Notably, the statute at issue waived the notification requirement if the woman stated in writing that her husband was not the biological father of the fetus-so the Supreme Court held that a man whose paternity was not in question nonetheless did not have the right to know his spouse was seeking an abortion. ${ }^{175}$ Therefore, the prebirth parentage order would not create any new rights of the intended parent against another party. Just as currently the biological father of a fetus who is married to the biological mother-a man whom state law clearly identifies as the father of any resulting child-does not have the ability either to compel his wife to terminate the pregnancy or to prevent her from obtaining an abortion, securing parental status in advance of the child's birth would not create new claims against the pregnant woman. ${ }^{176}$

Importantly, this means that intended parents would not have the ability to prevent the pregnant woman from seeking an abortion, or to force her to have an abortion if the intended parents changed their mind regarding the pregnancy. For example, if prenatal testing revealed an abnormality in the fetus, and the intended parents declared that they no longer wished to be the

173. Such parallel status would apply to existing damages claims related to pregnancy. If a surrogate were negligently injured and miscarried, for example, the surrogate would potentially have legal claims related to her own injuries. The intended parents, however, would be the proper parties to bring a claim related to the death of the fetus, such as a claim for emotional distress.

174. Planned Parenthood of Southeastern Pa. v. Casey, 505 U.S. 833 (1992).

175. Id. at $908-09$.

176. It is worth noting, however, that to the extent a formal declaration of prebirth parentage arguably increases that person's stake in continuation of the pregnancy, it implies that a woman's right to abortion relies upon minimizing men's status as fathers. 
parents of the child, they would be unable to withdraw their status as parents. Conversely, if a surrogate decided to terminate her pregnancy, the intended parents could not prevent her from doing so, nor would they have any legal claims against her based on her decision to terminate. ${ }^{177}$

\section{D.Implications}

Prebirth parentage orders are most appealing in the context of surrogacy. As has been demonstrated above, existing parentage regimes that apply only after birth are inadequate to resolve the tangible problems of parentage that arise in the context of ART.

Such orders have promise, however, even in more traditional realms. As highlighted in Section III.B, intent is also underutilized and unrecognized in the context of unwed fathers. Intent as a general theory has often been rejected as a potential parentage regime particularly in the context of fathers, as it is assumed that recognizing intent to be a parent must also recognize intent not to be a parent and thereby release fathers from child support obligations. Prebirth parentage orders demonstrate that this need not be the case. A prebirth parentage order, for obvious reasons, would not be issued merely to say "do not list Person $\mathrm{X}$ as a legal parent," without also providing a new parent willing to assume the obligations of legal parenthood. Such orders could therefore be utilized to formally recognize the plans of an unwed father to be a parent, without putting child support obligations of unwilling fathers in jeopardy.

Similarly, prebirth parentage orders could serve as a path into parenthood for many types of nontraditional parents. Same-sex couples often begin a life as co-parents of a child that is the biological child of one of the two parents. In jurisdictions in which the second parent is unable to utilize protections such as the marital presumption, if the family lives in a jurisdiction without same-sex marriage or second-parent adoptions by a same-sex second parent, the parent without a biological link to the child can be left without legal protection of that relationship. Prebirth parentage orders could be used in such a context to cement parentage rights of both partners, rather than relying on existing regimes that fail to adequately recognize such nontraditional parental units.

Finally, prebirth parentage orders could be used in a context that is not yet employed in any state: parentage by more than two parents. Although joint parenting by more than two adults is currently more theoretical proposal ${ }^{178}$

177. For example, the intended parents could not sue the surrogate for damages in the amount of the cost of preparing for the arrival of a child, or for emotional distress. The sole "compensation" in such an arrangement would be that to the extent the surrogacy agreement compensated the surrogate for her pregnancy, the intended parents might be excused from paying compensation tied to events such as the birth that never took place.

178. See generally Jacobs, Why Just Two, supra note 43. 
than reality, prebirth parentage orders provide an unambiguous and clear rule of recognizing an even less traditional parenting unit.

\section{CONCLUSION}

Empowering courts to look to written intent will improve parentage determinations in four ways. First, seeking out a declaratory judgment of parentage sets the bar relatively high as to showing intent, thus facilitating serious parenting intentions and encouraging responsible parenting. ${ }^{179}$ Second, having a final determination of parentage before birth not only provides a swift resolution to conflicts over parentage, but may help prevent them. As discussed above, surrogates often seek to detach emotionally from the pregnancy and think of the growing fetus as someone else's child. To the extent that such an understanding is legally, formally memorialized before or during the pregnancy, the surrogate is further encouraged to view her pregnancy in a way that will minimize any post-birth conflict. Third, prebirth parentage determinations would extend protections to children who are currently left vulnerable due to the indeterminacy of current parentage laws. Finally, the two major ambiguities in how courts currently deal with intent will be resolved: intent is the first best answer to determine parentage, rather than an answer of last resort; and second, intent is assessed at conception using Johnson $v$. Calvert's definition of intent to create a child, rather than intent as to the care of a child post-birth.

Importantly, this deals only with intent to opt in to parentage. It deals with the problems that arise when there are too many possible parents. In other words, it will not provide a method for people who would otherwise be legally responsible for the child to be declared nonparents, unless an intended parent ready to assume their obligations signs on. ${ }^{180}$

179. As a corollary, this will also ensure that people who do not truly intend to become parents cannot "accidentally" be deemed legal parents. This is not to say that intent as a "first best" answer will excuse from parenthood anyone who does not want to be a parent--this Article does not propose eliminating biology as one tool in a parentage regime, for example, so unwed biological fathers who do not seek parenting rights will nonetheless be liable for child support. To the extent that someone who would not otherwise be deemed a parent might be swept up in a very broad definition of manifesting intent, such as the boyfriend of a biological mother, setting the bar to show intent high will prevent such unintentional "intended" parenthood.

180. This refusal to allow people to bargain out of parenthood without a ready replacement is in keeping with current family law. See Baker, supra note 38 , at 8 . Melanie Jacobs argues that this helps to explain the treatment of unwed fathers. See Jacobs, My Two Dads, supra note 2, at 832 ("Perhaps Justice Stevens meant that in the paternity context, it is important to identify a second legal parent for the child but that in the adoption cases, the child's rights were adequately protected as another man had already willingly assumed the role of father. Thus, there was no reason to protect the rights of the unwed father."); see also Laura Oren, The Paradox of Unmarried Fathers and the Constitution: Biology 'Plus' Defines Relationships; Biology Alone Safeguards the Public Fisc, 11 WM. \& MARY J. WOMEN \& L. 47 (2004-2005). 
As this Article has shown, timing of intent to become a parent is important not just within familial boundaries, but in potential legal decisions that may take place long after intent has been-or not been-established. The law should encourage people to plan for parenthood, but the law currently fails to recognize, let alone facilitate, a forward-looking perspective. Of the existing doctrines used to identify parentage-marital presumption, biology, functional theories, and intent-only intent facilitates planning. Intent through time, however, is not treated consistently. Whereas today intent is given credit inconsistently, and often only as a tiebreaker when other parentage regimes do not provide an answer, intent should be the first principle looked to when a parentage dispute arises, at least to answer problems of "too many" potential parents. This incorporates factors that are salient to parenting, such as facilitating planning for children, and minimizes factors that are not, such as gender. 